\title{
Changes of Synaptic Density in the Primary Visual Cortex of the Macaque Monkey from Fetal to Adult Stage
}

\author{
J.-P. Bourgeois ${ }^{1}$ and P. Rakic ${ }^{2}$ \\ 'Laboratoire de Neurobiologie Moléculaire, Département des Biotechnologies, Institut Pasteur, 75724 Paris Cedex 15, \\ France and ${ }^{2}$ Section of Neurobiology, Yale University School of Medicine, New Haven, Connecticut 06510
}

The kinetics of synaptogenesis in the primary visual cortex (Brodmann's area 17) were analyzed by electron microscopy in 33 rhesus monkeys, ranging in age from the 50th embryonic day (E50) to 20 years. A series of overlapping electron micrographs (vertical probes) were examined at each age on sections of the upper bank of the calcarine fissure. Synaptic contacts were first observed in the E50 specimen in the subplate and marginal zone (prospective layer I). In the cortical plate itself, synapses appear between E65 and E89 starting in the prospective layer VI. By E112, after all cortical neurons have assumed their laminar positions, synapses situated predominantly on dendritic shafts were present at a low density throughout the full thickness of the cortical plate. Thereafter, synapses accumulate more rapidly on dendritic spines and by E144 an equal number of contacts are found on both spines and shafts. The density of synapses continues to increase exponentially in all layers and reaches the mean maximum density of about 90 synapses per $100 \mu \mathrm{m}^{3}$ of neuropil by the third postnatal month. During the next 2 postnatal years the density of synaptic contacts decreases only slightly to a mean of $80 / 100 \mu \mathrm{m}^{3}$ of neuropil. Around the time of puberty, however, synaptic density decreases more rapidly to reach the adult level of about 40$50 / 100 \mu \mathrm{m}^{3}$ of neuropil. The $40 \%$ decrease in the density of synaptic contacts occurring between 2.7 and 5 years represents a loss of about $\mathbf{5 0 0 0}$ synapses per second in the primary visual cortex of the two hemispheres, due primarily to the loss of asymmetric synapses situated on dendritic spines. The transient phase of high density of synaptic contacts located on dendrospines is shorter in thalamo-recipient layer IV than in either supra- or intragranular layers and is completed within the first postnatal year. It ends earlier in sublayer IVC than in layers IVAB and II-III, for example, reflecting biochemical and functional maturation of the different visual subsystems.

[Key words: synaptogenesis, striate cortex, primates, quantitative electron microscopy I

\footnotetext{
Received June 15, 1992; revised Nov. 23, 1992; accepted Jan. 11, 1993.

This research was supported by Grant EY02593 (P.R.), a Fogarty International Fellowship, and the CNRS (J.-P.B.). Pregnant monkeys were obtained from the breeding colonies at Yale University School of Medicine, which is supported in part by Program Project NS22807; and from the New England Primate Research Center, Southborough, MA, which is supported by Grant P51RR0016 from the Division of Research Resources. We thank Dr. P. Seghal for help with surgery and maintenance of animals, J. Musco and A. M. Le Sourd for preparing sections, Lois Angelo for typing, and Drs. P. S. Goldman-Rakic and K. Wikler for comments on the manuscript.

Correspondence should be addressed to P. Rakic, Section of Neurobiology, Yale University School of Medicine, 333 Cedar Street, New Haven, CT 06510.

Copyright (C) 1993 Society for Neuroscience $0270-6474 / 93 / 132801-20 \$ 05.00 / 0$
}

A detailed knowledge of the timing, sequence, and magnitude of synaptogenesis is essential for an understanding of the rules and mechanisms involved in the structural and functional development of the cerebral cortex. This information should provide a basis for the interpretation of experimental manipulations of cortical development, and genetic and acquired defects in the genesis of the visual system.

In the past two decades, the primate visual cortex has come to be associated with a remarkable capacity for functional and anatomical plasticity during pre- and postnatal developmental periods (e.g., Rakic, 1976, 1977b; Hubel et al., 1977; Blakemore et al., 1978, 1981). It is generally agreed that changes in cortical function are associated with corresponding alterations in the density and arrangement of synaptic circuits. Despite the obvious need for a comprehensive quantitative study of synaptic changes covering the complete period of maturation of the visual cortex, a detailed account is still lacking. The problem has been that both light and electron microscopic methods that show neuronal connections are not well suited for precise, complete, and comprehensive quantification, particularly in large brains that mature over a prolonged time. Previous quantitative analyses of synaptogenesis in the primate cortex that have suggested a transient phase of high density of synapses during infancy have been limited in the developmental ages sampled, in the selection of cortical laminae analyzed, and in the manner of data presentation (O'Kusky and Colonnier, 1982; Mates and Lund, 1983a,b; Rakic et al., 1986; Lund and Harper, 1991; Lund and Holbach, 1991 ; Ungersböck et al., 1991; Zeilinski and Hendrickson, 1992). The quantitative data from these previous studies are difficult to compare directly with each other because of the variety of methods and modes of expressing the densities of synapses, as well as the differences in ages examined. For these reasons, in the present study we determined the number of synapses, both per unit area $\left(N_{a}\right)$ and per unit volume $\left(N_{v}\right)$ of neuropil, in order to allow comparison of our data with these diverse manners of presentations. We also decided to examine individual cases over a wide range of age, from embryonic stages to 20 years, rather than perform a cross-sectional analysis of many animals at only a few ages. This strategy provided reliable curves of overall changes in synaptic density throughout the life span of the rhesus monkey. Furthermore, we expressed synaptic density per unit of neuropil to avoid the problem of synaptic dilution due to the differential growth of other cellular elements in the nearby tissue. This method also enables us to estimate the absolute number of synapses lost within the primary visual cortex. The quantitative approach we have adopted can also distinguish between various synaptic categories (symmetricasymmetric) and pinpoint their postsynaptic location (soma, dendritic shaft, dendritic spine). Detailed, standardized, nor- 
Table 1. List of the specimens and probes utilized in the present study

\begin{tabular}{|c|c|c|c|c|c|c|c|}
\hline $\begin{array}{l}\text { Post- } \\
\text { concep- } \\
\text { tional } \\
\text { age (D) }\end{array}$ & $\begin{array}{l}\text { Embryonic }(\mathrm{E}) / \\
\text { postnatal }(\mathrm{P}) \\
\text { ages }\end{array}$ & $\begin{array}{l}\text { Number } \\
\text { of } \\
\text { animals }\end{array}$ & Sex & $\begin{array}{l}\text { Number } \\
\text { of EM } \\
\text { probes }\end{array}$ & $\begin{array}{l}\text { Number of } \\
\text { synapses } \\
\text { counted }\end{array}$ & $\begin{array}{l}\text { Number } \\
\text { of } \\
\text { probes } \\
\text { used } \\
\text { for } \\
\text { stereol- } \\
\text { ogy }\end{array}$ & $\begin{array}{l}\text { Total } \\
\text { number of } \\
\text { synapses } \\
\text { used for } \\
\text { stereology }\end{array}$ \\
\hline 50 & $\mathrm{E} 50$ & 1 & $?$ & 3 & 2 & 0 & 0 \\
\hline 65 & E65 & 1 & $?$ & 2 & 26 & 0 & 0 \\
\hline 89 & E89 & 1 & $\mathbf{M}$ & 2 & 47 & 0 & 0 \\
\hline 112 & E112 & 1 & $?$ & 2 & 262 & 1 & 164 \\
\hline 144 & E144 & 1 & $\mathbf{F}$ & 2 & 1733 & 1 & 903 \\
\hline 165 & $\mathrm{E} 165(=\mathrm{P} 0)$ & 1 & $?$ & 2 & 5498 & 1 & 1314 \\
\hline 173 & P8 (1 week) & 2 & $\mathbf{M}+\mathbf{F}$ & 3 & 8399 & 0 & 0 \\
\hline 179 & P14 (2 weeks) & 1 & $\mathbf{M}$ & 2 & 4896 & 1 & 1249 \\
\hline 185 & P20 (3 weeks) & 1 & $\mathbf{M}$ & 2 & 8109 & 0 & 0 \\
\hline 186 & P2l (3 weeks) & 1 & $\mathrm{~F}$ & 2 & 7080 & 1 & 2251 \\
\hline 187 & P22 (3 weeks) & 1 & $F$ & 2 & 8917 & 0 & 0 \\
\hline 226 & P61 (2 months) & 2 & $\mathrm{M}+?$ & 4 & 18,642 & 2 & 2511 \\
\hline 259 & P94 (3 months) & 2 & $\mathbf{M}+?$ & 3 & 15,385 & 1 & 1417 \\
\hline 261 & P96 (3 months) & 1 & $?$ & 2 & 11,691 & 1 & 1507 \\
\hline 299 & P134 (4 months) & 1 & $\mathbf{M}$ & 4 & 23,061 & 2 & 2755 \\
\hline 312 & P147 (5 inonths) & 1 & $?$ & 2 & 10,745 & 1 & 2010 \\
\hline 315 & P150 (5 months) & 1 & $\mathbf{M}$ & 2 & 8566 & 1 & 1236 \\
\hline 387 & P222 (7 months) & 1 & $F$ & 4 & 15,700 & 2 & 2269 \\
\hline 565 & P400 (1 year, 1 month) & 1 & $\mathbf{M}$ & 6 & 27,581 & 2 & 2495 \\
\hline 763 & P598 (1 year, 7 months) & 1 & $\mathbf{M}$ & 6 & 16,972 & 2 & 2346 \\
\hline 965 & P800 (2 years, 2 months) & 1 & $\mathbf{M}$ & 5 & 15,461 & 2 & 1779 \\
\hline 1108 & 2 years, 7 months & 1 & $\mathbf{M}$ & 5 & 17,146 & 2 & 2254 \\
\hline 1260 & 3 years & 1 & $\mathbf{M}$ & 6 & 18,703 & 2 & 2509 \\
\hline 1808 & 4 years, 5 months & 1 & $\mathbf{M}$ & 5 & 13,580 & 2 & 1861 \\
\hline 1990 & 5 years & 1 & $?$ & 5 & 15,070 & 3 & 2672 \\
\hline 2872 & 7 years, 5 months & 1 & $\mathbf{M}$ & 1 & 3245 & 1 & 1089 \\
\hline 3815 & 10 years & 1 & $\mathrm{~F}$ & 1 & 2657 & 1 & 897 \\
\hline 4910 & 13 years & 1 & $?$ & 1 & 1992 & 1 & 486 \\
\hline 6370 & 17 years & 1 & $?$ & 2 & 3886 & 2 & 1378 \\
\hline 7465 & 20 years & 1 & $?$ & 2 & 4381 & 2 & 1721 \\
\hline Total & & 33 & & 90 & 289,433 & 37 & 39,087 \\
\hline
\end{tabular}

Ages in days after conception are presented in the first column. Embryonic (E) and postnatal (P) ages (after birth) in days are presented in the second column.

mative data on the time course of synaptic development in the visual cortex during the entire pre- and postnatal periods in the rhesus monkey can be correlated with other cellular events and functional maturation, and offer valuable insights into possible developmental mechanisms. These quantitative data are needed in order to test the hypothesis that the initial production of synapses is controlled intrinsically while their stabilization or selective elimination after birth is determined by complex epigenetic mechanisms (see Bourgeois et al., 1986, 1989).

\section{Materials and Methods}

Animals. The present study is based on the analysis of 33 rhcsus monkeys (Macaca mulatta) of both sexes, ranging in age from embryonic day 50 (E50) to 20 years (Table 1). Puberty in both genders of this species takes place between 3 and 5 years after birth (Napier and Napier, 1967; Plant, 1988). Breeding and dating of pregnancies followed the procedures described previously (Rakic, 1972, 1973). In macaques, birth occurs $165 \mathrm{~d}$ after conception. Fetuses were delivered naturally or by cesarean section at this time. The animals were tranquilized with ke- tamine $(0.1 \mathrm{ml} / \mathrm{kg})$ and deeply anesthetized with sodium phenobarbital $(40 \mathrm{mg} / \mathrm{kg}$, with a solution at $50 \mathrm{mg} / \mathrm{ml}$ ) prior to transcardiac perfusion with $100-500 \mathrm{ml}$ of a phosphate-buffered saline solution ( $\mathrm{pH} \mathrm{7.4)} \mathrm{fol-}$ lowed by 1-2 liters of a phosphate-buffered fixative ( $\mathrm{pH} 7.4$ ) containing $1 \%$ paraformaldehyde and $1.25 \%$ glutaraldehyde. The brains were removed, immersed in the same fixative for $12 \mathrm{hr}$ at $4^{\circ} \mathrm{C}$, and then dissected and processed for electron microscopic (EM) examination.

Tissue preparation. Blocks of cerebral cortex were dissected from the middle third of the upper bank of the calcarine fissure in the right hemisphere (Fig. 1A). This site, which is situated within a binocular region of the peripheral field ( $+40^{\circ}$ eccentricity, according to Van Essen et al., 1984), was chosen because it can be located with relative accuracy in the brains of fetal and adult animals. The blocks were washed in 0.1 $M$ phosphate buffer with $5 \%$ sucrose, postfixed for $60 \mathrm{~min}$ in $1 \%$ osmium tetroxide in $0.1 \mathrm{~m}$ phosphate buffer with $5 \%$ sucrose, and then washed six times with $0.1 \mathrm{M}$ maleate buffer at $\mathrm{pH} 5$. The specimens were subsequently stained en bloc in $2 \%$ uranyl acetate for $60 \mathrm{~min}$ in $0.1 \mathrm{M}$ maleate buffer at $\mathrm{pH} 5$. After staining, the tissue was washed six times in $0.1 \mathrm{~m}$ maleate buffer, dehydrated in ethanols graded from $25 \%$ to $100 \%$, then in propylene oxide twice for $5 \mathrm{~min}$ and, finally, embedded in a mixture of Epon 812.

Semithin sections $(1 \mu \mathrm{m})$, cut across the full thickness of the cortex, were mounted on glass slides and stained with an aqueous solution of 

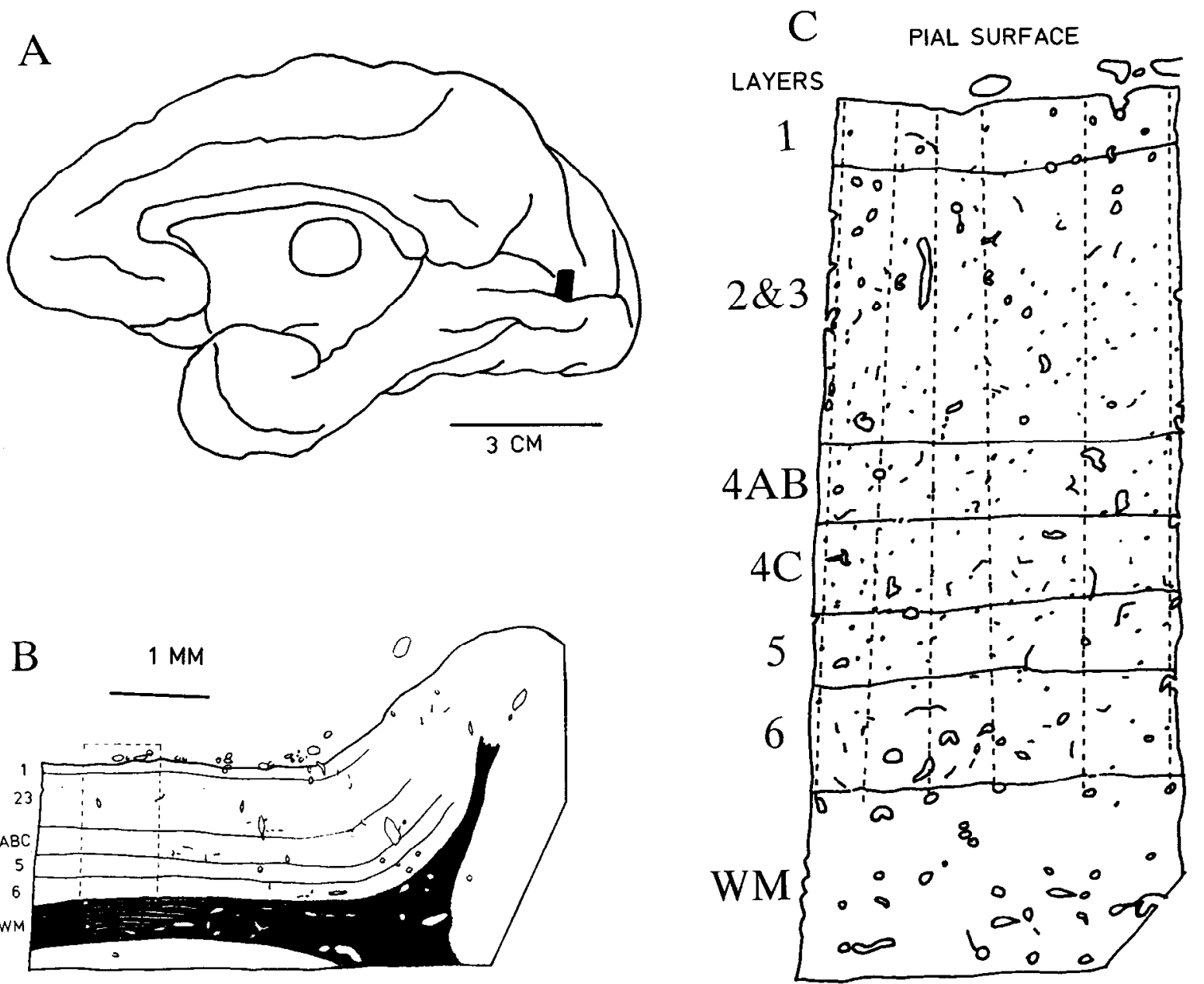

Figure 1. A, Medial surface of a cerebral hemisphere from a 3-year-old macaque displays the location in the middle third of the upper bank of the calcarine fissure (dark rectangle) from which tissue blocks were dissected. $B$. Camera lucida outline of a semithin section cut across the entire face of the block stained with toluidine blue. The smaller blocks were trimmed as indicated by the dashed line. $C$, Camera lucida drawing of a $1-\mu \mathrm{m}$-thick section cut across the surface of the trimmed section and stained with toluidine blue. The adjacent sections were cut ultrathin $(0.075$ $\mu \mathrm{m}$ ), stained, and prepared for analysis with the electron microscope. The EM probes were oriented parallel to the course of apical dendrites and perpendicular to the plane of the pial surface. Up to six vertical probes have been made from this single ultrathin section.

toluidine blue. The outline of each semithin section was drawn at low magnification using a camera lucida adapted to the light microscope (Fig. $1 B$ ). These drawings were used to determine the orientation of the sections of cortical tissue for further analysis. The middle third of the upper bank of the calcarine fissure was selected in each block, using transected blood vessels and the topology of the cortical surface as landmarks. Finally, a semithin section was cut from the trimmed block and drawn in full detail, using the camera lucida at $71 \times$ final magnification. This drawing included blood vessels, contours of the section, position of the white matter, and the cortical layers identified cytoarchitectonically (Fig. $1 C$ ). For the designation of the laminae we adopted the scheme and terminology proposed by Lund (1973; see also review in Billings-Gagliardy et al., 1974). However, it was difficult to distinguish the border between sublayers IVA and IVB and the results of these two sublayers are presented together. Several ultrathin sections adjacent to the final semithin section were cut on an LKB ultratome 4. The sections were placed on formvar-coated slot grids, stained with a solution of $3 \%$ ethanolic uranyl acetate for $10 \mathrm{~min}$ followed by $0.2 \%$ lead citrate, rinsed in distilled water, and allowed to dry before examination with a JEOL $100 \mathrm{~S}$ electron microscope. The thickness of the pale-gold interference color thin sections was estimated at $0.075 \mu \mathrm{m}$ by using the interference color technique and the small fold technique (Small, 1968).

Sampling procedure. Each thin section was oriented in the electron microscope using as a reference the drawing of the adjacent semithin section. The route of each probe was traced on the drawing, taking the pial surface, blood vessels, and other cellular structures as landmarks.
Each probe consisted of a series of overlapping micrographs that extended vertically from the pial surface to the white matter. This vertical sampling was selected to fit as closely as possible the vertical organization of ontogenetic columns, as defined by Rakic $(1978,1988)$, and to provide a reliable overview of the synaptic distribution in this radial direction. This vertical sampling does not bring any bias since horizontal sampling performed in the anterior cingulate cortex (B. Granger and J.P. Bourgeois, unpublished observations), and randomization procedure in the somatosensory cortex (Zccevic and Rakic, 1991), did not modify either the densities of synapses or the kinetics of their production. Depending on the age of the animal, between 60 and 120 photomicrographs were taken at a nominal magnification of $5000 \times$ for each probe. The actual magnification was verified by calibrated grating replica, photographed after each EM probe. The pictures were printed at a final magnification of $14,100 \pm 205( \pm S D ; n=73)$. Under these conditions, each EM probe was about 13-14 $\mu \mathrm{m}$ wide and spanned the full distance between the pial surface and the white matter (see example in Fig. 1C). One to six continuous probes spanning the entire cortical thickness were made for each age.

The size of the blocks dissected out from the brain was measured immediately after the perfusion and dissection, and then again after embedding in Epon. No shrinkage could be found in these blocks after processing for electron microscopy. This absence of shrinkage is confirmed by independent measurements made on the rostrocaudal length (the L-L1 length defined in Fig. 13 of Rakic and Yakovlev, 1968) of a large piece of tissue such as the corpus callosum dissected out from the same brains used in the present study (LaMantia and Rakic, 1990). The 


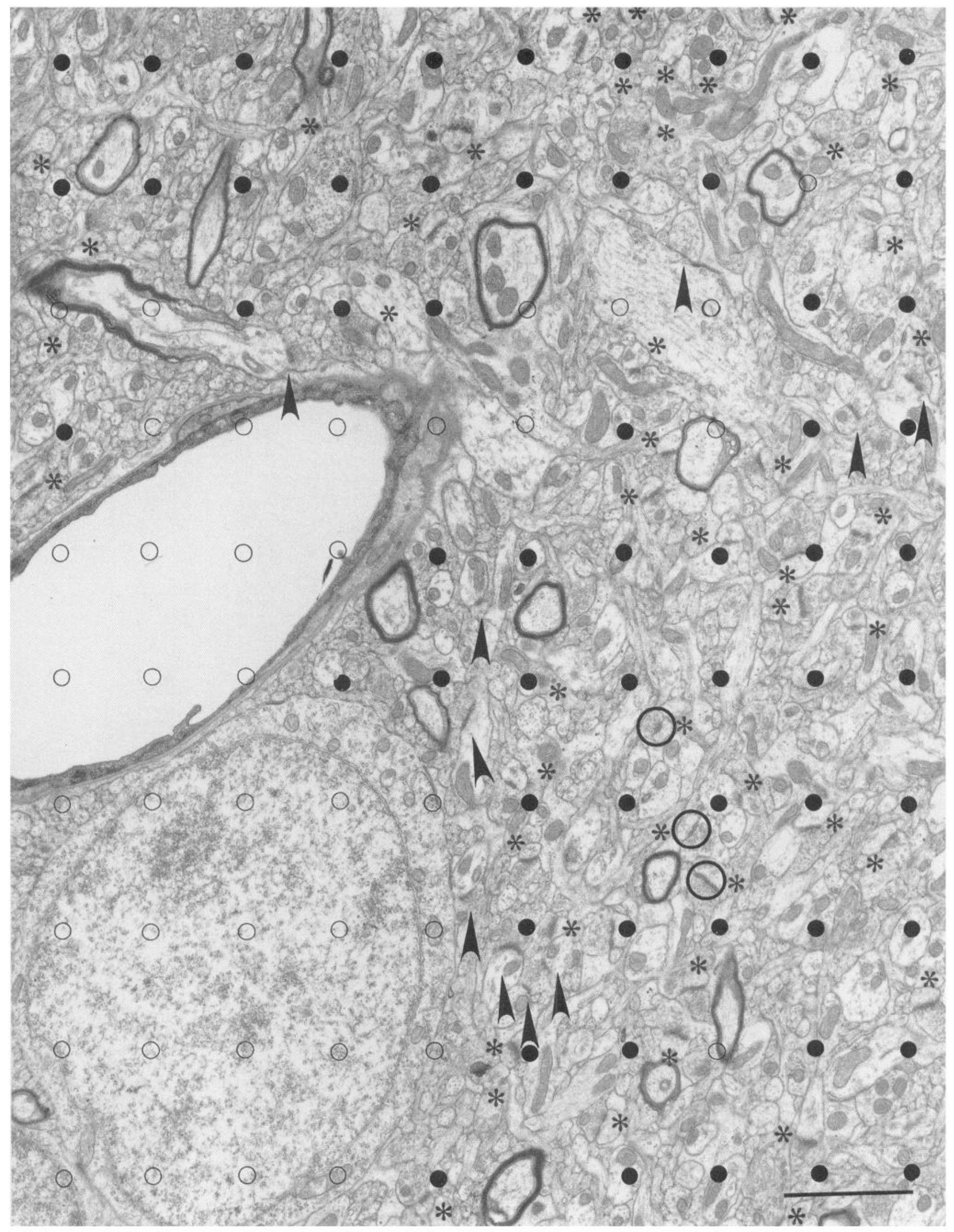

Figure 2. Electron micrograph from the upper part of layer III in the striate cortex of a 3-year-old macaque taken at the final magnification utilized for assembling the vertical probes. The percentage of neuropil as defined in Materials and Methods was determined using the set of 100 points superimposed on the electron micrographs. The solid circles are located over neuropil; the open circles are located on all other elements. The synaptopil, as defined in the Discussion, is outlined here by large open circles around selected synaptic contacts. Classification of synapses was made at this magnification with the help of a magnifying glass. Note that at this age more synaptic contacts are found on dendritic spines (asterisks) than on shafts (arrowheads). Scale bar, $2 \mu \mathrm{m}$. 
extent of the shrinkage was also checked at each step during the preparation of the thin sections. Some semithin sections and adjacent ultrathin sections were mounted side by side on glass slides. No shrinkage could be observed, even after staining with either toluidine blue or uranyl acetate and lead citrate, suggesting that the difference in the thickness of sections has no effect on the degree of tissue shrinkage. The only significant and measurable shrinkage was observed in most of the specimens during the making of the probes in the electron microscope. The longitudinal length of each EM probe was determined using the blood vessels and pial surface identifiable both in the photomontage and in its linear trace positioned on the light microscope drawing (Fig. $1 C)$. Usually, the total length of the EM probe was about $10 \%$ shorter than the total length of the corrcsponding line on the drawing of the semithin section. This shrinkage factor allowed the renormalization of the position of each cortical layer, determined on the semithin section drawn at the light microscope level, and recalculated for each of the EM probe photomontages. We also compared the three different calibration grids utilized throughout this entire study by making a series of electron micrographs on the same day and found no significant deformation between the oldest and the newest ones. No attempt was made to estimate the degree of shrinkage from exposure to aldehydes during the perfusion itself because it would have required surgery before perfusion for each individual case. This is not, however, a limitation in our study since we compared densities of synapses at different stages of maturation rather than estimate the absolute number of synaptic contacts. A total of 90 vertical probes were made for the present study, representing more than 10,000 photomicrographs, covering about 1.56 $\mathrm{mm}^{2}$ of cortical tissue, on which 289,433 synaptic contacts were marked, counted, measured, and classified.

Counting procedure. The neuropil is commonly considered as the space occupied by small neuronal and glial cell processes (Peters et al., 1976). We adopted this definition and, therefore, excluded from our sampling area the perikarya of neurons and glial cells, blood vessels with their pericytes, myelinated axons, large apical dendrites, and extracellular space (Fig. 2). The fraction of cortical surface occupied by neuropil on each EM probe was estimated following a procedure described by Cooper and Rakic (1983). A set of 100 points regularly spaced on a transparent plastic sheet, covering a $20 \mu \mathrm{m} \times 13 \mu \mathrm{m}$ surface area, was placed systematically over each of the $20 \mu \mathrm{m}$ intervals along the probe. The percentage of points located over the neuropil was recorded (Fig. 2) and used for the calculation of the area of neuropil in each 20 $\mu \mathrm{m}$ vertical interval. Synaptic contacts were identified as apposed preand postsynaptic plasma membranes accompanied by more than one synaptic vesicle in the terminal bouton (for illustration of these definitions, see Bourgeois et al., 1989; Zecevic et al., 1989). The synaptic contacts were counted separately within each of the evenly spaced 20 $\mu \mathrm{m}$ intervals, starting from the pial surface and continued to the white matter. Knowing the total number of synaptic contacts and the area of neuropil per interval allowed the calculation of the density of synaptic contacts per unit area $\left(N_{a}\right)$ of neuropil in each interval and indirectly in each cortical layer and sublayer.

Stcreological corrections. One sampling bias inherent to EM analysis is that, due to the thickness and the angles of ultrathin sections, the smallest synaptic profiles may be missed (Coupland, 1968). Therefore, the density of synapses per unit volume $\left(N_{v}\right)$ may be systematically underestimated (Anker and Cragg, 1974). In addition, the number of synapses in a volume of tissue depends on the geometry and size of synaptic profiles, which may vary during the course of development (see review in Mayhew, 1979). In the present study we examined whether the time course of synaptogenesis is substantially changed after two most commonly used stereological corrections of the sampling biases (reviewed in Colonnier and Beaulieu, 1985).

In the first correction we adapted the Coupland stereological formula (1968), using the computer program proposed by Anker and Cragg (1974). This calculation, made with an IBM-PC computer, gave the corrected value of the mean length of the synaptic contacts and their density per unit of volume of neuropil $\left(N_{v}\right)$ for each cortical layer. The sampling of one-fifth of the synaptic contacts (i.e., in one $20 \mu \mathrm{m}$ interval out of five) in one or two of the vertical probes was considered to be sufficient to provide a reliable correction. Synapses were categorized into 12 different types according to their location (on dendrospines, dendroshafts, axons, or soma) and EM morphology (asymmetric, symmetric, or undetermined). These ultrastructural features have been illustrated previously (Bourgeois et al., 1989; Zecevic et al., 1989). This classification was considered as adequate and convenient for the present

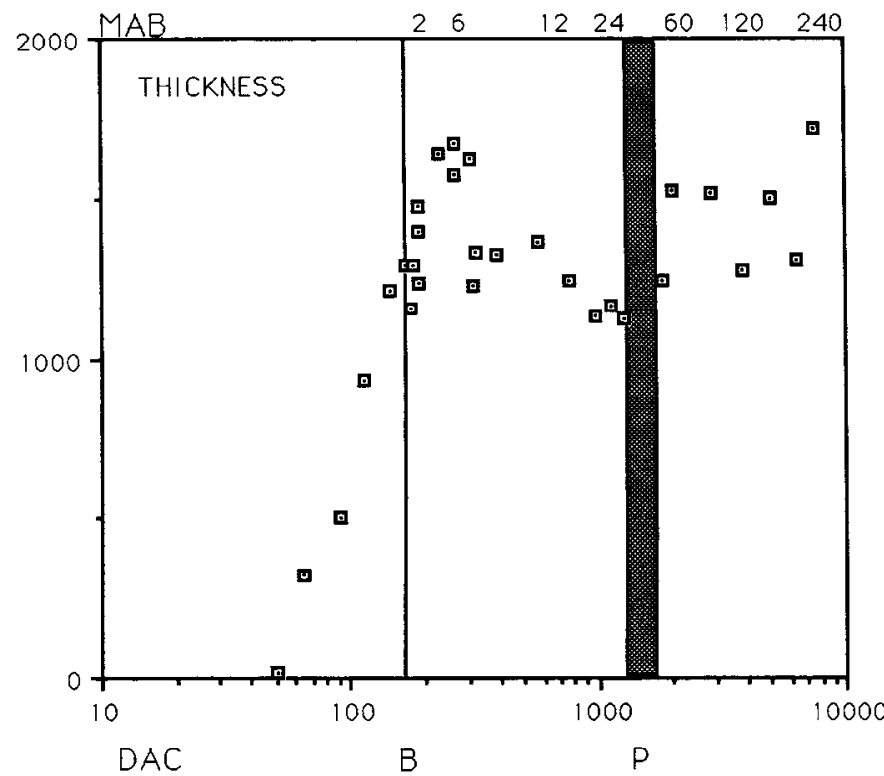

Figure 3. Thickness of the striate cortex as a function of time after conception. All cortical layers are pooled together. Thickness is expressed in microns. Each point is the mean of two to six vertical probes. $M A B$, months after birth; $D A C$, days after conception; $B$, birth; $P$, puberty.

quantitative study. However, one must keep in mind that the types of synapses sampled are extremes of a continuum that merge from one into the other (Colonnier 1968, 1981). In each category, the length of each individual synaptic profile was measured using a tracing table connected to an MOP-videoplan KONTRON microcomputer. This first procedure was chosen because its frequent use by other authors allows comparison of data.

In the second procedure we used a stereological correction recommended by Colonnier and Beaulieu (1985). We added this procedure because it has been empirically tested on striate cortex of the macaque monkey (Colonnier and Beaulieu, 1985) and it is more simple. It requires only data on density per unit area $\left(N_{a}\right)$ and the mean length of the synaptic profiles $(L)$ to determine the density per unit volume of tissue $\left(N_{v}=N_{a} / L\right)$. We considered it necessary to test whether the kinetics of synaptogenesis are the same when two very different stereological corrections are used.

\section{Results}

\section{Thickness of the cortex and its layers}

All neurons of the primary visual cortex of the rhesus monkey have been generated by E100 (Rakic, 1974) and have acquired their appropriate positions within the cortical plate around E1 10 (Rakic, 1975). However, the thickness of the cortical mantle continues to increase until the second postnatal month and thereafter slightly decreases during a period of about 2 years (Fig. 3). This decline is followed by a second phase of a slow but steady increase in thickness that continues throughout puberty and adulthood.

\section{Proportion of neuropil}

In the two youngest specimens (E50 and E65) the neuropil is rather sparse (Fig. 4). Only in the marginal zone (prospective layer I) could we observe some clearly defined synapses intermingled among neuritic expansions. There is also a large amount of extracellular space at these early ages that diminishes dramatically in the second half of gestation when cortical tissue becomes well packed with nerve cells and their processes. The percentage of neuropil per unit area of cortical tissue continues 

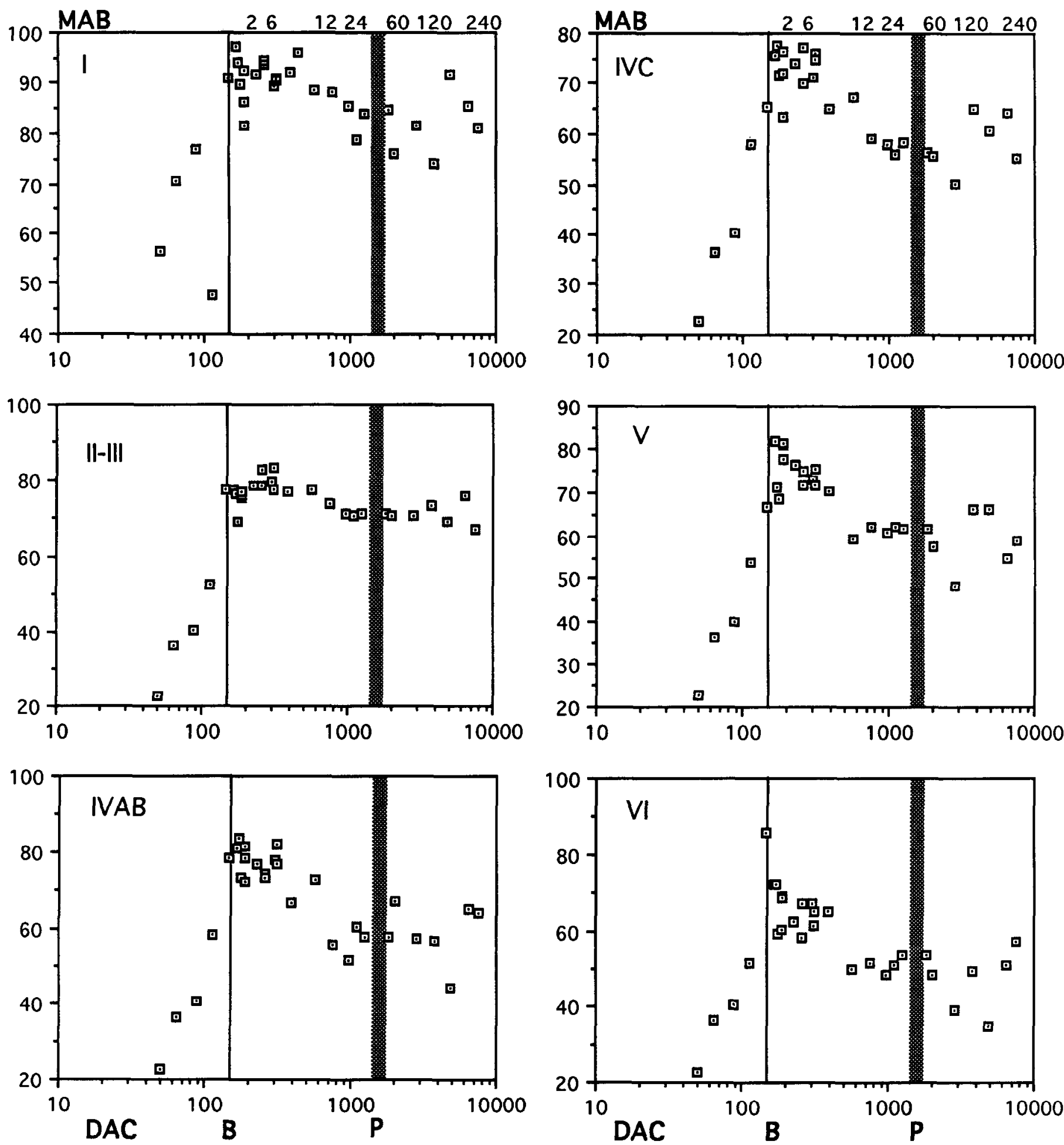

Figure 4. Changes in the percentage of cortical tissue occupied by the neuropil as a function of time during development of the cortical layers. Each point represents the mean value obtained from one to six vertical probes. $M A B$, months after birth; $D A C$, days after conception; $B$, birth; $P$, puberty. $M A B$ and $D A C$ are presented on a semilogarithmic scale.

to increase until term $(\mathrm{E} 165=\mathrm{P} 0)$, when it reaches its maximum value. The percentage of neuropil per vertical probe is the highest in layer I, with values of over $80 \%$ recorded at birth. It is within the $70-80 \%$ range in the supragranular and granular layers, and falls to $30-70 \%$ in the infragranular layers. This gradient of values may be related to the amount of extrinsic and intrinsic connections and the presence of myelinated fibers in the infraand supragranular layers. The percentages of neuropil per unit area of cortical tissue remain relatively constant during the first 18 months and then seem to decline slightly, but continuously, throughout adulthood. This decrease is more pronounced in the infragranular than in supragranular layers. For example, the area 
occupied by neuropil is $80 \%$ in layer I in the 20 -year-old animal, $67 \%$ in supragranular layers, $55 \%$ in layer IVC, and $50-60 \%$ in the infragranular layers (Fig. 4). The cortex of old monkeys in our material is not noticeably thinner than during adolescence despite a decreasing percentage of neuropil. This may be due, at least partially, to the continuous process of myelination that, in primates, continues until old age (Yakovlev and Lecours, 1967; K. Gibson, personal communication).

\section{Early phase of synaptogenesis}

The very first morphologically defined synaptic contacts in the occipital lobe could be observed above and below the cortical plate, in layer I and the subplate zone of the E50 specimen, respectively (Figs. 5, 6). The same pattern was observed in the E65 specimen. During the next fetal month, synaptic contacts accumulate rapidly in these two locations. The synaptic contacts in the cortical plate were rare but clearly present in the E89 specimen (Figs. 5, 6). The first contact in the cortex appears between E65 and E89 and is located in the lower part of the cortical plate where the earlier-generated neurons of the layer VI have already migrated to their final positions (Rakic, 1974, 1975). Therefore, layer VI neurons receive the first synaptic contacts in the visual cortex, before neurons of the most superficial layers have been generated. By E112, after all the neurons have acquired their final positions, synapses can be observed throughout the cortical plate (Figs. 5, 6). Almost all of the synapses encountered at these early stages are localized on dendritic shafts, although a few synapic contacts can be found on spines (see Figs. 8, 9). The mean packing density of synaptic contacts in the cortical plate remains low compared to those in layer I and the subplate zone. For example, at E1 12 the mean density is between 4 and 6 synapses per $100 \mu \mathrm{m}^{3}$ of neuropil in the cortical plate, compared to 10 synapses per $100 \mu \mathrm{m}^{3}$ in the marginal zone. At E144 the density of synapses becomes more uniformly distributed across all cortical layers, and after this late fetal age synaptogenesis proceeds rapidly and relatively uniformly across all cortical layers.

\section{Phase of rapid production of synapses}

Between E144 and the fifth postnatal month (P150), the density of synapses per unit area of neuropil increases exponentially (Figs. 5-7). This rapid accumulation of synaptic contacts takes place simultaneously in all of the cortical layers (see Figs. 6, 9). The time of onset and the rate of this accumulation is similar when we consider either the total number of synapses $\left(N_{\text {tot }}\right)$ per vertical probe (Fig. 5, top) or the density of synapses per unit area $\left(N_{a}\right.$; Figs. 5,6$)$ or per unit volume of neuropil $\left(N_{v}\right.$; Figs. 79) using either the Anker and Cragg (1974) stereological correction (Fig. $7 A$ ), or the Colonnier and Beaulieu (1985) correction (Fig. $7 B$ ). There is remarkably little individual variation in the rate of synaptic production among the 13 specimens that were available to the analysis of this phase of development (Fig. 5).

\section{Phase of high synaptic density}

After reaching a mean maximum level of about 30 synapses per $100 \mu \mathrm{m}^{2}$ of neuropil (Fig. 5), or $80-90$ per $100 \mu \mathrm{m}^{3}$ (Figs. 7, 8) during the third postnatal month, the density of synapses remains high, with a slight decrease during the next two years, that is, throughout infancy and adolescence. This slanted "plateau" of high synaptic density is evident when results are presented per unit area $\left(N_{a}\right.$; Fig. 5) or per unit volume of neuropil
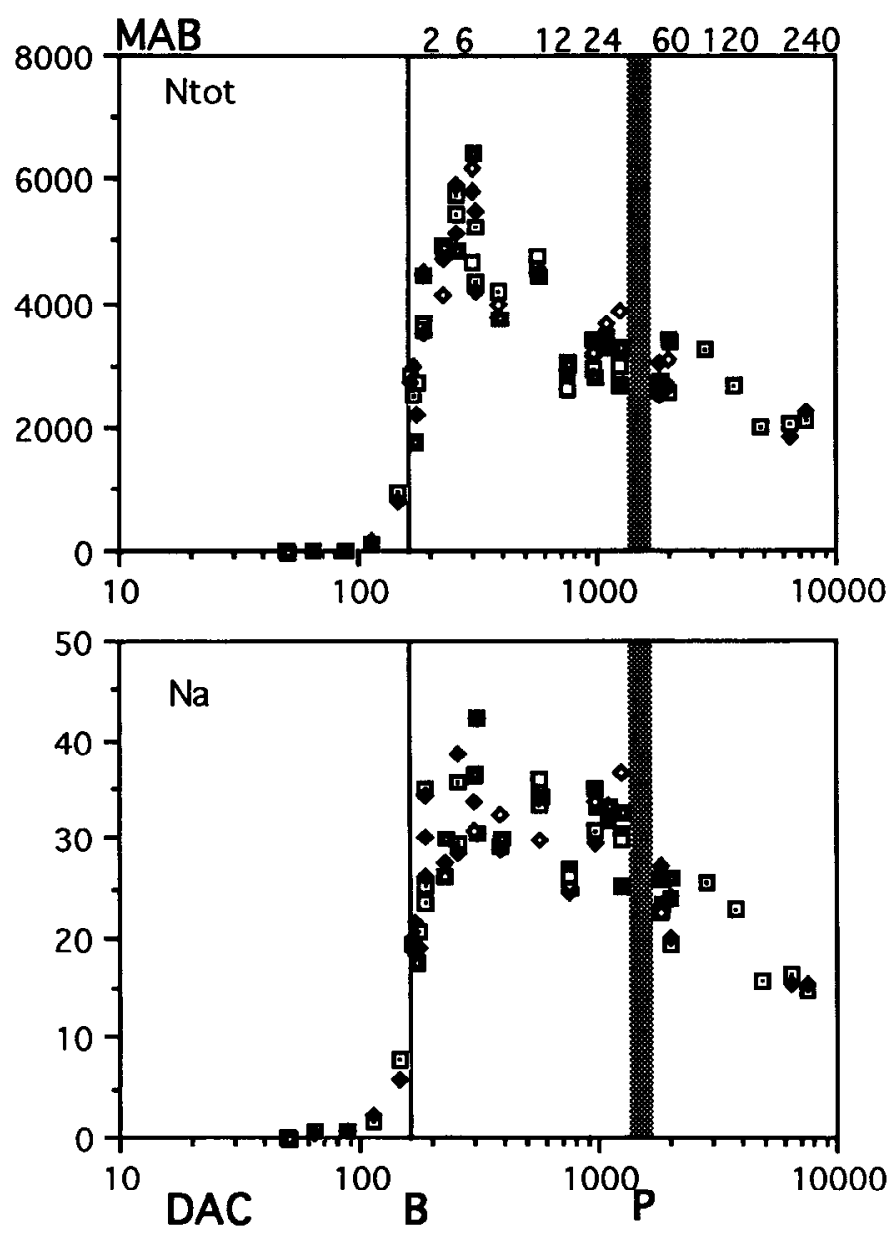

Figure 5. Top, Total number $\left(N_{\mathrm{tol}}\right)$ of synaptic contacts per EM probe. Time is represented on the $\mathrm{x}$-axis on a logarithmic scale. Each point represents the counts in a single vertical probe $13 \mu \mathrm{m}$ wide and 0.075 $\mu \mathrm{m}$ thick. The point symbols used here are not related to those used in the other figures. Bottom, The density $\left(N_{a}\right)$ of synaptic contacts (all types and layers pooled together) per $100 \mu \mathrm{m}^{2}$ of neuropil as a function of time. At each age, one to six probes were counted and plotted on a semilogarithmic scale. $M A B$, months after birth; $D A C$, days after conception; $B$, birth; $P$, puberty.

( $N_{v}$; Fig. 7), calculated by either of the two stereological corrections.

During the first 3 postnatal years, the density of synapses pcr unit area of neuropil $\left(N_{a}\right)$ varies within a relatively large range of values (25-36 contacts per $100 \mu \mathrm{m}^{2}$ of neuropil). These interand intraindividual variabilities were not dependent on the number of vertical probes. This became apparent when we added all animals within the age bracket before puberty $(2.7$ and 3 years) and after puberty (4.5 and 5 years) and when we augmented up to six the numbers of vertical probes at these age groups. The variability in the density of synaptic contacts was often larger inside one section of cortex in a single specimen than the variability found between two specimens of similar ages. For example, variability in density of synapses was large (ranging from 25 to 36 ) in the 3-year-old animal and small (range, 31-34) in the 2-year-old and 7-month-old animals (Fig. 5).

After puberty, which in macaque monkeys occurs around the third year of age (Napier and Napier, 1967; Plant, 1988), the density of synaptic contacts becomes significantly lower. The 

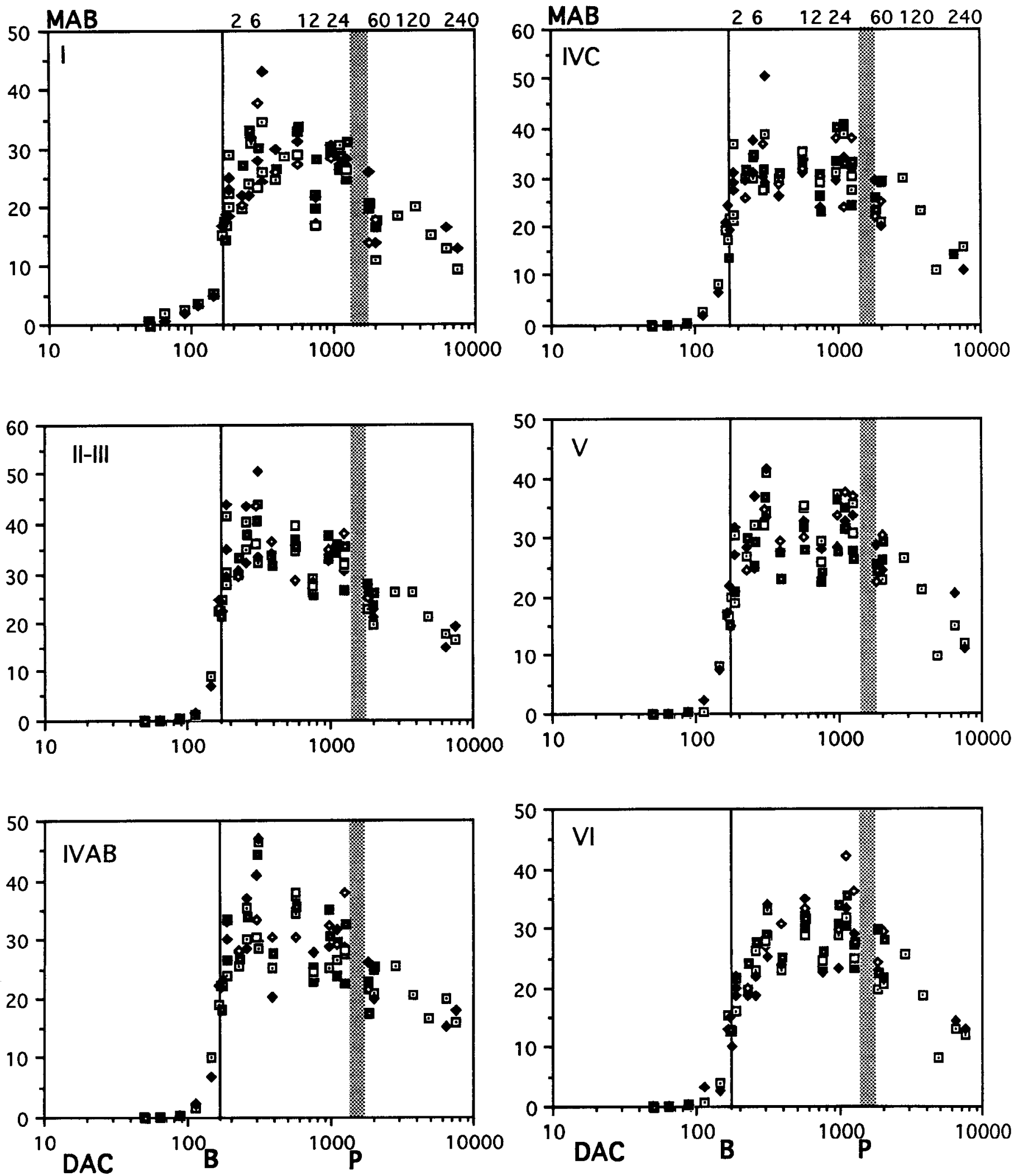

Figure 6. Density of all synaptic contacts expressed per $100 \mu \mathrm{m}^{2}$ of neuropil $\left(N_{a}\right)$, in each cortical layer, as a function of time. At each age, synapses in one to six different probes were counted and the data represented on a semilogarithmic scale. $M A B$, months after birth; $D A C$, days after conception; $B$, birth; $P$, puberty. 

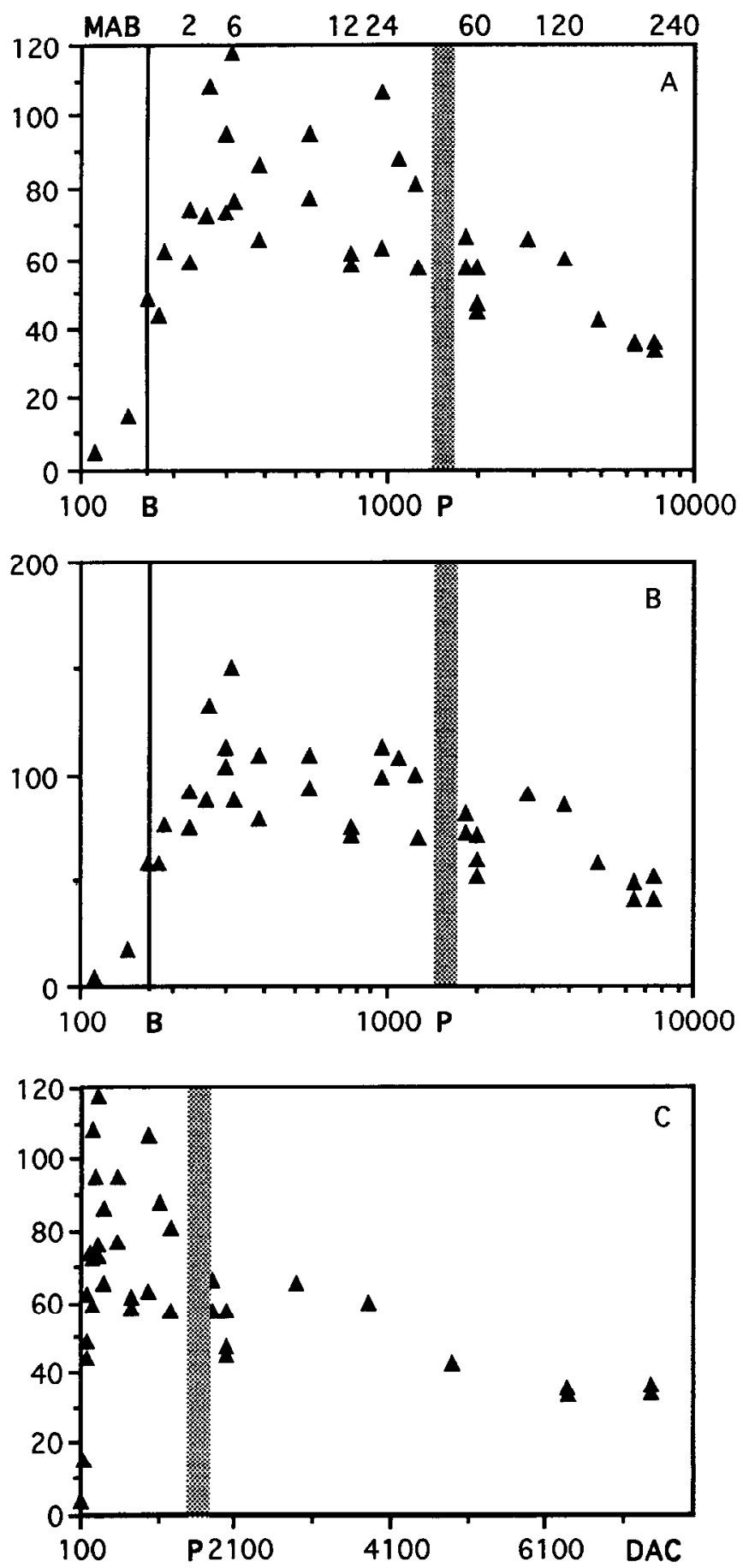

Figure 7. Density of all synaptic contacts (triangles) expressed per unit volume $\left(100 \mu \mathrm{m}^{3} ; N_{v}\right)$ of neuropil, as a function of time, in all cortical layers pooled together. The kinetics of synaptogenesis are similar before (Fig. 5) and after using the stereological corrections of Anker and Cragg (1974) shown in $A$, and of Colonnier and Beaulieu (1985) shown in $B$. Times in $A$ and $B$ are represented on semilogarithmic scales. The more rapid decline in synaptic density around the time of pubcrty $(P)$ is morc explicit when the time is given on a linear scale $(C)$. $M A B$, months after birth; $D A C$, days after conception; $B$, birth.

mean density of all synapses (all layers and all types pooled together) measured between 3 months (P94) and 3 years after birth is $31.7 \pm 4.1$ synapses per $100 \mu \mathrm{m}^{2}(n=49)$. However, between 4.5 and 20 years the mean value decreases to $21.2 \pm$ $4.2(n=17)$. The timing of this decrease of the density is similar

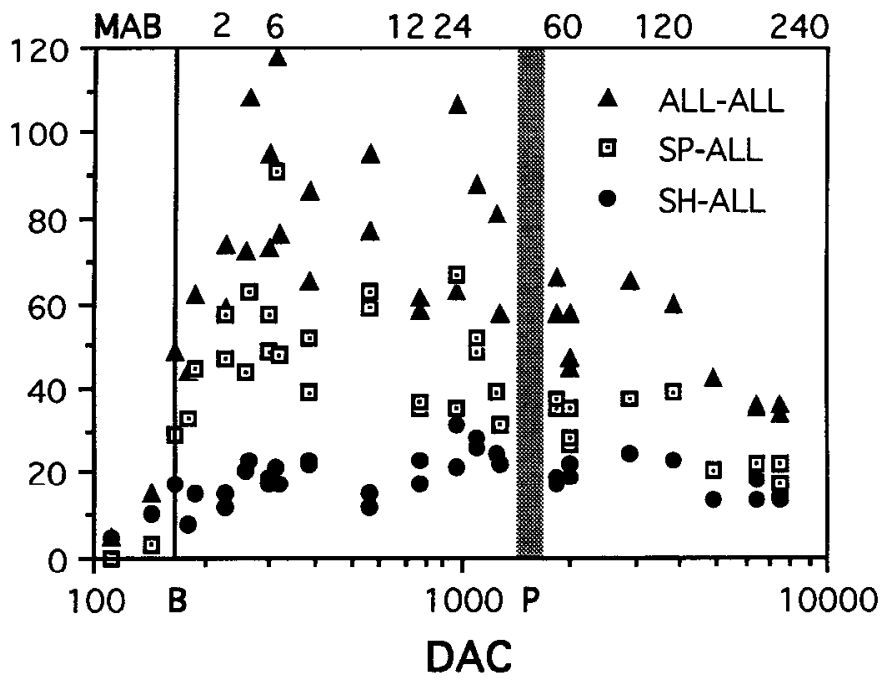

Figure 8. Density of all synaptic contacts (triangles), and those situated on dendritic spines (squares) and dendritic shafts (circles), expressed per unit volume $\left(100 \mu \mathrm{m}^{3} ; N_{v}\right)$ of neuropil from E1 12 to adulthood, in all the cortical layers pooled together. The density of synapses was corrected according to the Anker and Cragg formula (1974). $M A B$, months after birth; $D A C$, days after conception; $B$, birth; $P$, puberty. Semilogarithmic scale.

to that found after stereological corrections as described below. The density of synapses per unit area and per unit volume of neuropil seems to decrease further during the second decade after birth in this primate species (Figs. 5, 7).

The graphs in Figures 5 and 7 display the changes in the density of the general population of synapses within the striate cortex. These "envelope" curves display the kinetics for different cortical layers and classes of synaptic contacts. Differences in the magnitude of the peak synaptic density in individual cortical layers become apparent during the "en plateau" phase. For example, the highest density of 47 synaptic contacts per $100 \mu \mathrm{m}^{2}$ was recorded in layers II and III at Pl47 (Fig. 6), while the lowest density of 28 synapses per $100 \mu \mathrm{m}^{2}$ is found at the same age in layer VI (Fig. 6). In layer VI the maximal density is maintained during the entire adolescence period, but at a lower level than in layers II and III (Fig. 6). These differences are maintained after the stereological corrections (Fig. 9).

\section{Synaptic density per unit volume of neuropil}

Two stereological corrections were made to determine whether densities of synapses expressed per unit volume of neuropil have time courses different from densities expressed per unit area of neuropil (see Materials and Methods). The mean density of synapses per unit volume of neuropil $\left(N_{v}\right)$ between 2 months (P61) and 3 years is $18.5 \%$ higher with the Colonnier and Beaulieu correction (98 synaptic contacts per $100 \mu \mathrm{m}^{3}$ of neuropil) than with the Anker and Cragg correction (80 synaptic contacts per $100 \mu \mathrm{m}^{3}$ ). However, the time course of synaptogenesis assessed by either stereological method is remarkably similar (Fig. 7), and is not different from the time course for estimates of the density expressed per unit area of neuropil $\left(N_{a}\right)$ shown in Figure 5. We confirm here that the increase in density of synaptic contacts occurs simultaneously in all the cortical layers of the visual cortex, as has been observed previously in other cortical areas (Rakic et al., 1986). The mean maximum density $\left(N_{p}\right)$ of synapses is reached at about the same time, 2-3 months after 

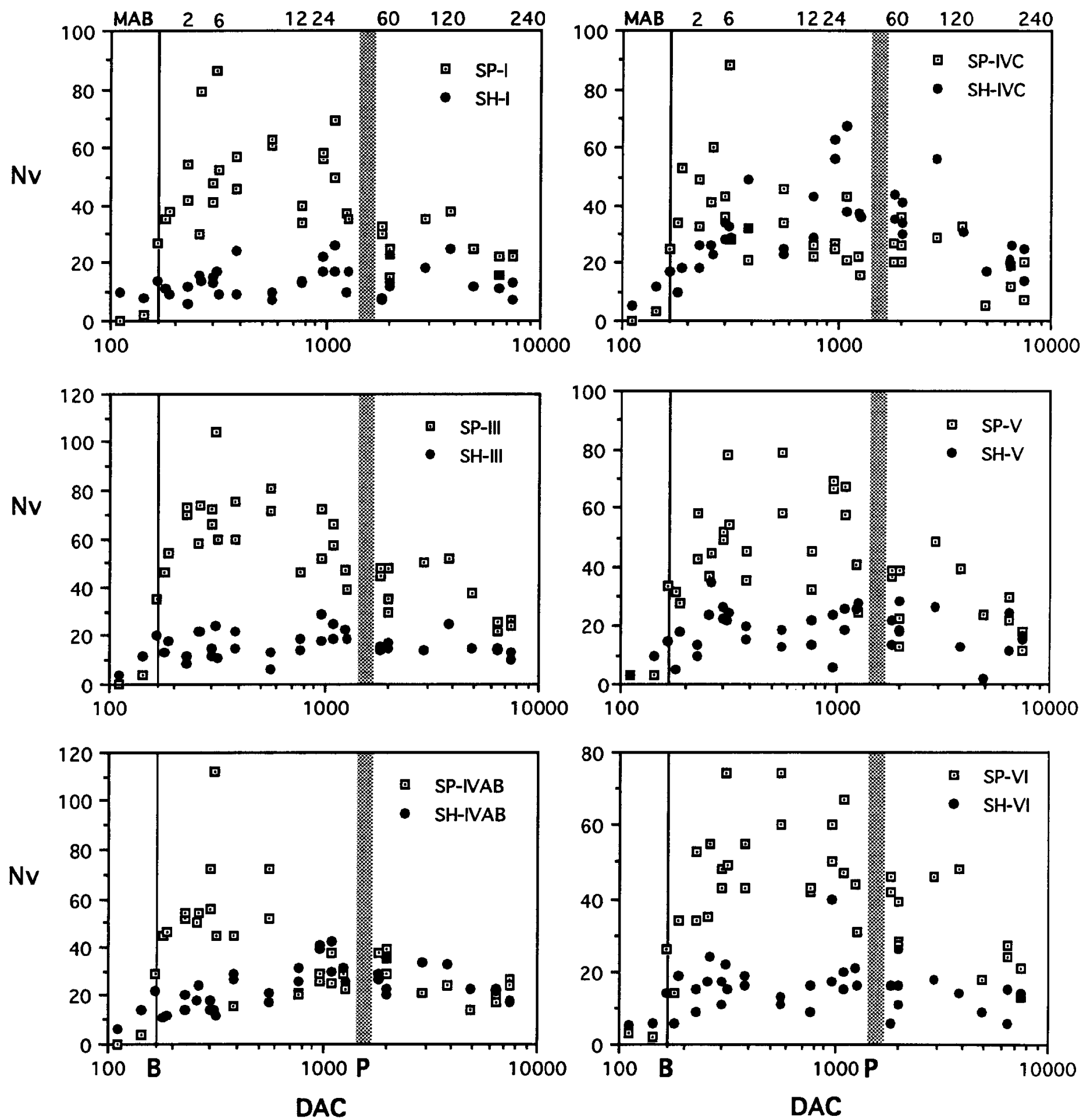

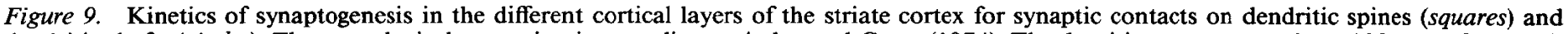

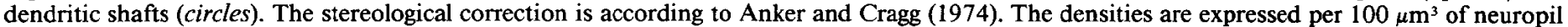
$\left(N_{v}\right)$ and presented on a semilogarithmic scale. $M A B$, months after birth; $D A C$, days after conception; $B$, birth; $P$, puberty.

birth (P61-P94), in all cortical layers (all types of synapses pooled together). Second, we found that the densities of synapses are slightly higher in the supragranular layers as compared to the infragranular layers. For example, during infancy and adolescence (from 3 months to 3 years) the Anker and Cragg (1974) correction yields a mean value of about 91 synaptic contacts per $100 \mu \mathrm{m}^{3}$ of neuropil in layers II and III, compared to the 70 per $100 \mu \mathrm{m}^{3}$ found in layer VI (Fig. 9).

The highest density of synaptic contacts calculated by either of these two stereological corrections is maintained in all the cortical layers 3 months and 3 years after birth (Fig. 7). The densities of synapses observed during infancy and adolescence 


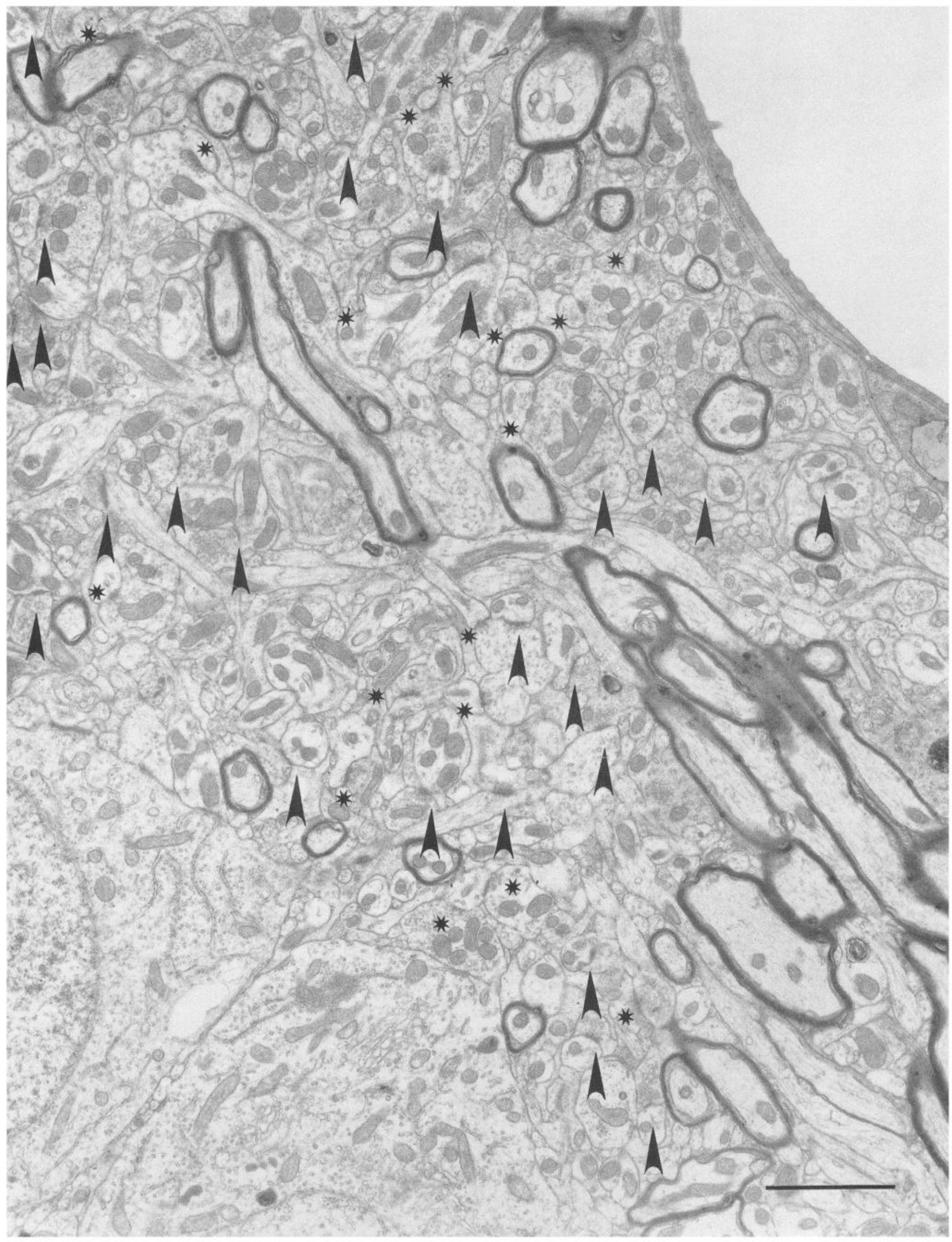

Figure 10. Electron micrograph of layer IVC $\alpha$ in the striate cortex of a 3-year-old male macaque. At this age, slightly more synaptic contacts in layer IVC $\alpha$ are situated on dendritic shafts (arrowheads) than on dendritic spines (stars), which is at variance with findings in the supra- and infragranular layers on the same section (for comparison, see Fig. 2). Scale bar, $2 \mu \mathrm{m}$. 
Table 2. Percentages of the asymmetric (A) and symmetric (S) synaptic contacts expressed as a function of time in each cortical layer

\begin{tabular}{|c|c|c|c|c|c|c|c|c|c|c|c|c|c|c|}
\hline \multirow[b]{2}{*}{ Age } & \multicolumn{2}{|l|}{ I } & \multicolumn{2}{|c|}{ II-III } & \multicolumn{2}{|c|}{ IVAB } & \multicolumn{2}{|c|}{ IVC } & \multicolumn{2}{|l|}{$\mathrm{V}$} & \multicolumn{2}{|l|}{ VI } & \multicolumn{2}{|l|}{ All } \\
\hline & A & $S$ & A & $S$ & $\mathrm{~A}$ & $S$ & A & $S$ & $\mathrm{~A}$ & $S$ & $\mathrm{~A}$ & $\mathrm{~S}$ & $\bar{A}$ & $S$ \\
\hline E89 & 48 & 33 & & & & & & & & & 35 & 47 & 44 & 37 \\
\hline E112 & 68 & 18 & 35 & 29 & 27 & 34 & 18 & 6 & 18 & 9 & 52 & 8 & 36 & 23 \\
\hline E144 & 53 & 35 & 34 & 35 & 35 & 23 & 27 & 33 & 22 & 49 & 37 & 25 & 34 & 33 \\
\hline E165 & 50 & 14 & 43 & 17 & 27 & 24 & 40 & 22 & 45 & 13 & 49 & 11 & 40 & 18 \\
\hline P14 & 85 & 12 & 90 & 8 & 60 & 9 & 57 & 4 & 94 & 3 & 75 & 16 & 71 & 8 \\
\hline P21 & 58 & 21 & 65 & 14 & 38 & 9 & 47 & 3 & 60 & 25 & 58 & 21 & 51 & 11 \\
\hline P61 & 63 & 12 & 56 & 16 & 53 & 18 & 53 & 19 & 63 & 14 & 72 & 14 & 58 & 16 \\
\hline P61 & 63 & 15 & 48 & 17 & 48 & 23 & 44 & 30 & 57 & 24 & 56 & 21 & 51 & 22 \\
\hline P94 & 74 & 16 & 71 & 9 & 76 & 10 & 55 & 20 & 64 & 17 & 66 & 10 & 68 & 13 \\
\hline P96 & 63 & 16 & 54 & 24 & 46 & 30 & 43 & 30 & 41 & 34 & 49 & 32 & 51 & 26 \\
\hline P134 & 85 & 4 & 63 & 10 & 65 & 12 & 47 & 18 & 54 & 17 & 61 & 12 & 62 & 12 \\
\hline P134 & 62 & 21 & 70 & 13 & 53 & 22 & 49 & 30 & 56 & 22 & 57 & 21 & 58 & 21 \\
\hline P147 & 56 & 27 & 46 & 31 & 60 & 27 & 50 & 34 & 61 & 27 & 64 & 24 & 54 & 29 \\
\hline P150 & 48 & 20 & 46 & 20 & 57 & 16 & 40 & 29 & 49 & 24 & 59 & 19 & 48 & 22 \\
\hline $\mathrm{P} 222$ & 70 & 14 & 64 & 15 & 61 & 14 & 52 & 18 & 60 & 20 & 65 & 14 & 62 & 16 \\
\hline $\mathrm{P} 222$ & 61 & 26 & 60 & 19 & 53 & 25 & 58 & 21 & 61 & 10 & 59 & 23 & 59 & 21 \\
\hline $\mathrm{P} 400$ & 77 & 12 & 72 & 12 & 61 & 15 & 48 & 24 & 62 & 23 & 71 & 10 & 65 & 16 \\
\hline P400 & 60 & 15 & 60 & 15 & 61 & 16 & 49 & 30 & 54 & 23 & 61 & 19 & 57 & 19 \\
\hline P598 & 69 & 16 & 75 & 16 & 56 & 28 & 69 & 18 & 73 & 17 & 80 & 14 & 71 & 18 \\
\hline P598 & 66 & 19 & 67 & 20 & 37 & 29 & 70 & 19 & 56 & 25 & 70 & 16 & 67 & 21 \\
\hline P800 & 48 & 23 & 53 & 23 & 41 & 25 & 43 & 34 & 50 & 28 & 54 & 33 & 49 & 26 \\
\hline P800 & 67 & 17 & 55 & 27 & 47 & 39 & 53 & 37 & 50 & 37 & 50 & 35 & 54 & 31 \\
\hline $2 \mathrm{Y} / 7 \mathrm{M}$ & 64 & 25 & 48 & 32 & 40 & 42 & 36 & 44 & 39 & 46 & 59 & 27 & 48 & 35 \\
\hline $2 \mathrm{Y} / 7 \mathrm{M}$ & 71 & 15 & 51 & 29 & 35 & 40 & 35 & 44 & 43 & 36 & 48 & 34 & 48 & 32 \\
\hline $3 Y$ & 57 & 18 & 75 & 16 & 40 & 39 & 49 & 27 & 36 & 34 & 46 & 30 & 60 & 23 \\
\hline $3 Y$ & 69 & 12 & 68 & 13 & 44 & 29 & 55 & 24 & 68 & 15 & 74 & 16 & 65 & 16 \\
\hline $4 \mathrm{Y} / 5 \mathrm{M}$ & 61 & 20 & 59 & 22 & 47 & 35 & 43 & 40 & 63 & 23 & 68 & 20 & 57 & 26 \\
\hline $4 \mathrm{Y} / 5 \mathrm{M}$ & 70 & 23 & 60 & 29 & 60 & 24 & 63 & 28 & 60 & 24 & 60 & 23 & 62 & 26 \\
\hline $5 \mathrm{Y}$ & 81 & 5 & 75 & 9 & 66 & 17 & 60 & 13 & 60 & 17 & 64 & 21 & 70 & 12 \\
\hline $5 Y$ & 52 & 32 & 56 & 25 & 49 & 21 & 52 & 26 & 44 & 29 & 47 & 29 & 51 & 26 \\
\hline $5 Y$ & 70 & 14 & 72 & 15 & 55 & 23 & 47 & 26 & 51 & 24 & 54 & 22 & 59 & 20 \\
\hline $7 \mathrm{Y} / 5 \mathrm{M}$ & 44 & 21 & 35 & 32 & 28 & 42 & 21 & 43 & 23 & 40 & 24 & 34 & 30 & 35 \\
\hline $10 \mathrm{Y}$ & 43 & 32 & 35 & 33 & 38 & 28 & 22 & 33 & 23 & 48 & 47 & 33 & 34 & 34 \\
\hline $13 Y$ & 57 & 18 & 54 & 19 & 40 & 10 & 51 & 8 & 54 & 18 & 57 & 25 & 52 & 16 \\
\hline $17 Y$ & 73 & 16 & 72 & 13 & 63 & 13 & 71 & 12 & 67 & 14 & 75 & 8 & 71 & 13 \\
\hline $17 Y$ & 66 & 20 & 58 & 12 & 56 & 18 & 52 & 28 & 65 & 14 & 59 & 18 & 59 & 18 \\
\hline $20 \mathrm{Y}$ & 60 & 12 & 52 & 14 & 52 & 9 & 58 & 14 & 50 & 15 & 47 & 15 & 53 & 13 \\
\hline $20 \mathrm{Y}$ & 51 & 25 & 50 & 13 & 47 & 19 & 52 & 18 & 55 & 18 & 51 & 20 & 51 & 18 \\
\hline
\end{tabular}

In the eighth column (All) are the lists of the percentages of asymmetric (A) and symmetric (S) synaptic contacts in all layers pooled together.

(from 3 months to 3 years) are consistently higher compared to values found in the adults (from 4.5 years to 20 years): $36 \%$ higher after the Colonnier and Beaulieu correction (98 vs 62 synaptic contacts per $100 \mu \mathrm{m}^{3}$; Fig. $7 B$ ), 39\% after the Anker and Cragg correction (80 vs 48 synaptic contacts per $100 \mu \mathrm{m}^{3}$; Fig. $7 \mathrm{~A}$ ), and $32 \%$ when synaptic density is calculated per unit area (31 vs 21 synaptic contacts per $100 \mu \mathrm{m}^{2}$; Fig. 5). These values are close to the $34 \%$ recorded in 6-month-old Macaca fascicularis by O'Kusky and Colonnier (1982). The amplitude of this transient high density of synaptic contacts in our material is larger in layers II and III (41\%) than in layers IVC and VI (35\%) using the Anker and Cragg correction. The accelerated decline of synaptic density during puberty $(2.7-5$ years) is observed whether the density is expressed per unit area (Figs. 5, 6 ) or per unit volume of neuropil after using two very different stereological corrections (Fig. $7 A, B$ ). It is also more explicit when the results are plotted on a real time scale rather than on a logarithmic time scale (Fig. $7 C^{-}$). The fact that three very different methods of presentation of the data give the same final kinctics of synaptogenesis can be taken as a confirmation of the validity of our observation.

\section{Ratio between axospine and axoshaft synapses}

We used the stereological correction of Anker and Cragg (1974) to compare the densities of synaptic contacts situated on dendritic spines versus dendritic shafts. Almost all of the initial synaptic contacts observed at embryonic stages E65 and E89 are found on dendritic shafts (Figs. 8,9). However, in the second half of gestation, after the completion of neurogenesis and mi- 
gration at E112, synaptic contacts can be observed also on the dendritic spines. Both types of synaptic contacts increase in frequency at a similar rate until E144. After this age, the rate of synaptogenesis on dendritic spines accelerates more rapidly. As a result, the ratio between synaptic contacts on dendritic shafts and on dendritic spines becomes reversed. Between E144 and the fifth postnatal month (P150), the majority of new synapses are formed on dendritic spines. This exponential increase in the density of synapses situated on spines occurs simultaneously in all cortical layers (Fig. 9). By the third postnatal month, the proportions of axospines and axoshaft synapses are stabilized at about $75 \%$ and $25 \%$, respectively. At all ages examined, the proportion of all synaptic contacts on neuronal cell soma ranged from $0.1 \%$ to $2 \%$.

During infancy and adolescence, the magnitude of the transient redundancy in the density of synaptic contacts situated on dendritic spines (44\%) is more than three times larger than that of contacts on dendritic shafts $(12 \%)$ in all cortical layers. The mean numbers of synapses per $100 \mu \mathrm{m}^{3}$ of neuropil before and after puberty arc, respectively, 51 and 28 synapses on spines, and 20 and 18 on shafts. Synapses located on dendritic shafts reach a plateau usually at the same age as those on spines, but at a considerably lower density, and they exhibit less individual variability (Fig. 8). The magnitude of this transient high density of synapses situated on dendritic spines is larger in the supragranular layers II-III (42\%), which contain mostly corticocortical connections, than in the infragranular layer VI (36\%), which forms predominantly reciprocal connections with subcortical structures (Fig. 9). These differences are smaller and even slightly reversed for the synapses situated on dendritic shafts (12\% and $17 \%$, respectively, in the same cortical layers II-III and VI).

Two striking exceptions to the general course in the ontogeny of synaptic density occur in layer IV. The rapid phase of production of synaptic contacts on dendritic spines in this layer is truncated compared to that in either supra- or infragranular layers. In sublaycrs IVAB the density of the synapses begins to decrease significantly soon after 1 year (P400 specimen) and becomes equivalent to that of contacts localized on dendritic shafts well before puberty (Fig. 9). In layer IVC the rapid phase of production of synaptic contacts situated on dendritic spines is even shorter, ending already by the eighth month (P222). In layer IVC the onset of synaptogenesis on dendritic shafts takes place at approximately the same embryonic stage as in the other cortical layers. However, at variance with what occurs in supraand infragranular layers, the increase of synapses situated on dendritic shafts in sublayer IVC is more rapid (Fig. 9). The production phase in IVC is followed by a second reversal in the absolute densities of axoshaft versus axospine contacts and the synaptic contacts on dendritic shafts become again slightly more numerous (Figs. 9, 10). The accumulation of contacts on dendritic shafts continues during adolescence, and yields eventually higher proportions of contacts on dendritic shafts $(62 \%)$ than on dendritic spines (37\%; see also Fig. 10). In contrast, during the same period in layer III more contacts are present on dendritic spines $(72 \%)$ than on dendritic shafts $(26 \%$; see also Fig. 2). This change in layer IVC may be the result of newly formed synapses situated on shafts, or a reflection of relocation of synaptic boutons from the spines to the shafts. Large fluctuations in the densities of synaptic contacts on dendritic shafts are observed around the time of puberty (Fig. 9). After puberty, the densities of synaptic contacts on both dendritic spines and dendritic shafts in layer IV decline slowly (Fig. 9).

\section{Ratio between asymmetric and symmetric synaptic contacts}

Overall, we found larger numbers of asymmetric than symmetric synaptic contacts in all layers throughout the life span of the macaque monkey (Table 2). However, examination of the ratio of asymmetric and symmetric synapses during development shows a large degree of individual variability. For example, before birth, most synaptic contacts are asymmetric $(38 \%$; range, $34-44 \%$ ), while $27 \%$ are symmetric (range, $18-37 \%$ ). The remaining contacts could not be classified with certainty. During infancy and adolescence, up to 3 years after birth, $57 \%$ of all the synaptic contacts are asymmetric (range, 48-71\%) and 20\% are symmetric (range, $8-35 \%$ ). During adulthood (from 4.5 years to 20 years after birth), these proportions do not change significantly and are, respectively, 54\% (range, 30-71\%) and 21\% (range, 12-35\%). During infancy and adolescence, sublayers IVAB and IVC seem to have lower proportions of asymmetric contacts than the supragranular and infragranular cortical layers (Table 2). After puberty (between 4.5 and 20 years) these proportions become more homogeneous.

In the group of synapses located on dendritic spines (Table 3 ), more contacts are asymmetric $(65 \%$; range, $41-100 \%)$ and only $12 \%$ are symmetric (range, $0-29 \%$ ). The relatively large range is surprising, but it remains similar at all ages examined. In the group of synapses located on dendritic shafts (Table 3), about equal proportions of synaptic contacts are asymmetric $(39 \%)$ and symmetric (37\%).

\section{Summary of results}

We have identified six broad phases of synaptogenesis in the visual cortex of macaque monkey: (1) an initial phase that lasts for about $50 \mathrm{~d}$ (E50-E100) when synapses are initially encountered mostly above and below the cortical plate; (2) an early phase of inside-out synaptogenesis within the cortical plate that continues for the next $50 \mathrm{~d}$ (E100-E150); (3) an exponential phase of synaptogenesis in all cortical layers, which takes place during the last 2 weeks of gestation and extends through the first 3 postnatal months; (4) a phase of high synaptic density that continues, with slow decline, during adolescence; (5) a phase of more rapid decrease in synaptic density that occurs mainly during puberty (between 2.7 and 5 years of age); and (6) a phase of relative stability that lasts throughout adult life (between 5 and 20 years).

\section{Discussion}

The neuroanatomical and physiological methods presently available do not allow a complete account of the changes in specific synaptic contacts throughout the main stages of cortical maturation in the large primate brain. Golgi staining (e.g., Lund and Holbach, 1991) or tracing techniques (e.g., Kakic, 1976, $1977 \mathrm{~b})$ reveal changes in laminar distribution of the subpopulations of ncurons, dendritic spincs, or terminal ficlds of various afferent systems. More recent histochemical and immunocytochemical methods expose additional levels of complexity in the structural and biochemical composition of cortical synaptic architecture (e.g., Jones, 1986; Rakic et al., 1986; Somogyi, 1987; Kuljis and Rakic, 1989). We provide here a general description of the course of synaptogenesis in the striate cortex, spanning the whole life of the rhesus monkey. The results are discussed below in the context of the maturation of various cellular, biochemical, and physiological events that occur in the visual system. 


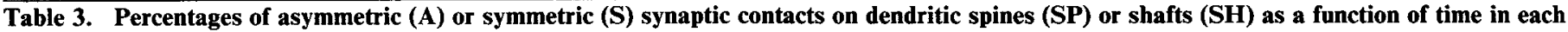
cortical layer

\begin{tabular}{|c|c|c|c|c|c|c|c|c|c|c|c|c|c|c|}
\hline \multirow[b]{3}{*}{ Age } & \multicolumn{4}{|c|}{ I } & \multicolumn{4}{|c|}{ II-III } & \multicolumn{4}{|c|}{ IVAB } & \multicolumn{2}{|l|}{ IVC } \\
\hline & \multicolumn{2}{|l|}{ SP } & \multicolumn{2}{|l|}{ SH } & \multicolumn{2}{|l|}{$\mathrm{SP}$} & \multicolumn{2}{|l|}{ SH } & \multicolumn{2}{|l|}{$\mathrm{SP}$} & \multicolumn{2}{|l|}{$\mathrm{SH}$} & \multicolumn{2}{|l|}{ SP } \\
\hline & $\mathrm{A}$ & $\mathrm{S}$ & $\mathrm{A}$ & $S$ & $\mathrm{~A}$ & $\mathrm{~S}$ & $\mathrm{~A}$ & $\mathrm{~S}$ & $\mathrm{~A}$ & $\mathrm{~S}$ & $\mathrm{~A}$ & $\mathrm{~S}$ & $\mathrm{~A}$ & $S$ \\
\hline E89 & 100 & 0 & 46 & 35 & 0 & 0 & 35 & 47 & 0 & 0 & 0 & 0 & 0 & 0 \\
\hline E112 & 0 & 0 & 68 & 18 & 0 & 0 & 36 & 30 & 0 & 100 & 17 & 33 & 100 & 0 \\
\hline E144 & 80 & 13 & 47 & 43 & 57 & 17 & 26 & 42 & 53 & 15 & 30 & 26 & 47 & 11 \\
\hline E165 & 54 & 7 & 43 & 25 & 57 & 4 & 19 & 40 & 36 & 10 & 17 & 39 & 54 & 7 \\
\hline P14 & 96 & 3 & 55 & 40 & 96 & 1 & 67 & 30 & 63 & 7 & 54 & 16 & 16 & 12 \\
\hline $\mathbf{P} 21$ & 68 & 8 & 26 & 63 & 77 & 6 & 34 & 34 & 41 & 7 & 30 & 15 & 49 & 3 \\
\hline P61 & 69 & 7 & 30 & 34 & 12 & 7 & 28 & 60 & 61 & 11 & 35 & 35 & 63 & 4 \\
\hline P61 & 73 & 10 & 22 & 38 & 53 & 11 & 15 & 54 & 54 & 17 & 31 & 44 & 52 & 21 \\
\hline P94 & 90 & 3 & 48 & 42 & 83 & 3 & 47 & 25 & 85 & 3 & 52 & 30 & 63 & 15 \\
\hline P96 & 70 & 10 & 32 & 42 & 56 & 17 & 50 & 44 & 54 & 22 & 29 & 48 & 49 & 22 \\
\hline P134 & 93 & 1 & 63 & 15 & 72 & 3 & 31 & 35 & 73 & 1 & 32 & 52 & 66 & 2 \\
\hline P134 & 71 & 9 & 37 & 54 & 75 & 8 & 45 & 50 & 61 & 13 & 28 & 53 & 61 & 21 \\
\hline P147 & 63 & 19 & 23 & 71 & 60 & 21 & 9 & 82 & 66 & 23 & 25 & 56 & 59 & 24 \\
\hline P150 & 50 & 16 & 36 & 47 & 53 & 12 & 13 & 56 & 63 & 8 & 37 & 41 & 50 & 14 \\
\hline $\mathrm{P} 222$ & 82 & 8 & 45 & 26 & 75 & 8 & 37 & 33 & 68 & 7 & 58 & 17 & 75 & 5 \\
\hline $\mathbf{P} 222$ & 68 & 19 & 21 & 64 & 69 & 11 & 23 & 62 & 62 & 15 & 44 & 41 & 61 & 15 \\
\hline P400 & 78 & 10 & 66 & 33 & 75 & 8 & 34 & 56 & 69 & 10 & 42 & 26 & 57 & 17 \\
\hline P400 & 67 & 11 & 24 & 40 & 68 & 9 & 21 & 46 & 66 & 11 & 38 & 40 & 74 & 14 \\
\hline P598 & 79 & 6 & 39 & 46 & 92 & 2 & 37 & 53 & 69 & 16 & 47 & 36 & 71 & 11 \\
\hline P598 & 78 & 6 & 39 & 48 & 77 & 10 & 39 & 50 & 50 & 18 & 52 & 36 & 73 & 13 \\
\hline P800 & 55 & 16 & 28 & 42 & 64 & 13 & 25 & 50 & 41 & 17 & 44 & 32 & 35 & 37 \\
\hline P800 & 75 & 13 & 40 & 33 & 63 & 17 & 35 & 53 & 64 & 32 & 43 & 47 & 64 & 21 \\
\hline $2 \mathrm{Y} / 7 \mathrm{M}$ & 76 & 14 & 39 & 48 & 57 & 25 & 28 & 50 & 45 & 30 & 37 & 56 & 28 & 35 \\
\hline $2 \mathrm{Y} / 7 \mathrm{M}$ & 82 & 9 & 20 & 44 & 58 & 20 & 28 & 56 & 44 & 32 & 31 & 54 & 44 & 37 \\
\hline $3 Y$ & 82 & 3 & 40 & 33 & 77 & 16 & 49 & 26 & 53 & 25 & 37 & 33 & 75 & 16 \\
\hline $3 Y$ & 69 & 11 & 13 & 41 & 90 & 5 & 47 & 38 & 49 & 27 & 34 & 49 & 52 & 19 \\
\hline $4 \mathrm{Y} / 5 \mathrm{M}$ & 66 & 14 & 42 & 47 & 65 & 16 & 39 & 41 & 60 & 24 & 35 & 45 & 51 & 33 \\
\hline $4 \mathrm{Y} / 5 \mathrm{M}$ & 73 & 19 & 60 & 35 & 70 & 18 & 34 & 60 & 68 & 20 & 50 & 29 & 71 & 16 \\
\hline $5 Y$ & 83 & 1 & 79 & 9 & 81 & 7 & 63 & 14 & 68 & 16 & 64 & 12 & 57 & 16 \\
\hline $5 Y$ & 66 & 22 & 29 & 50 & 65 & 15 & 39 & 46 & 54 & 19 & 51 & 26 & 56 & 17 \\
\hline $5 Y$ & 78 & 4 & 54 & 37 & 78 & 9 & 54 & 32 & 57 & 25 & 53 & 21 & 58 & 18 \\
\hline $7 \mathrm{Y} / 5 \mathrm{M}$ & 51 & 17 & 32 & 32 & 39 & 27 & 20 & 50 & 34 & 37 & 24 & 45 & 22 & 36 \\
\hline $10 \mathrm{Y}$ & 64 & 10 & 15 & 60 & 40 & 25 & 24 & 48 & 50 & 20 & 31 & 34 & 23 & 22 \\
\hline $13 Y$ & 68 & 7 & 31 & 45 & 59 & 10 & 42 & 40 & 46 & 3 & 37 & 13 & 54 & 0 \\
\hline $17 \mathrm{Y}$ & 83 & 5 & 55 & 34 & 81 & 7 & 61 & 22 & 60 & 14 & 66 & 13 & 70 & 20 \\
\hline $17 Y$ & 75 & 7 & 50 & 42 & 61 & 9 & 52 & 17 & 56 & 6 & 58 & 29 & 57 & 14 \\
\hline $20 \mathrm{Y}$ & 69 & 6 & 46 & 23 & 57 & 7 & 42 & 30 & 52 & 4 & 51 & 16 & 70 & 6 \\
\hline $20 \mathrm{Y}$ & 53 & 19 & 43 & 43 & 51 & 10 & 48 & 28 & 53 & 16 & 42 & 25 & 44 & 20 \\
\hline
\end{tabular}

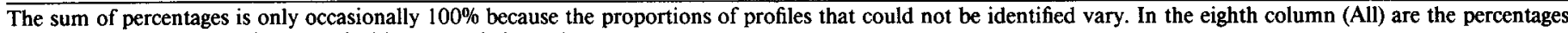
of these synaptic contacts in all cortical layers pooled together.

\section{Massive synaptic production during infancy}

The first synapses in the monkey neocortex are observed in layer I at E50, followed by layer VI between E65 and E89. However, the rapid rate of synaptogenesis begins sometimes between E1 12 and E144, 2 weeks after the end of neurogenesis (Rakic, 1974) and completion of neuronal migration (Rakic, 1975). The exponential phase of synaptogenesis subsides around the third postnatal month (P94 specimen). The course of synaptogenesis does not seem to change significantly at E165 as a consequence of birth and exposure to visual stimulation. Furthermore, in the perinatal period the general population of synapses accumulates at the same rate in all cortical layers. The present observations, together with the finding that binocular enucleation (Rakic, 1988) and premature exposure to light (Bourgeois et al., 1989) does not change the tempo of synaptic production, suggest that the rate of early synaptic production may be innately programmed, rather than induced by visual stimulation. This view, however, does not exclude the possibility that discrete differences in maturational rates of specific classes of synapses, observed immediately after birth, occur in response to diverse functional states induced by the different visual stimulations (Hubel et al., 1977; Bourgeois et al., 1989; Lund and Holbach, 1991).

Anatomical (Rakic, 1976, 1977b; LeVay and Stryker, 1979) and physiological (Hubel and Wiesel, 1977) studies suggested that the segregation of the geniculocortical afferents into ocular dominance columns of layer IV in the striate cortex may result, at least in part, from elimination of synaptic terminals from the 
Table 3. Extended.

\begin{tabular}{|c|c|c|c|c|c|c|c|c|c|c|c|c|c|}
\hline \multirow{2}{*}{\multicolumn{2}{|c|}{$\frac{\text { IVC }}{\text { SH }}$}} & \multicolumn{4}{|l|}{ V } & \multicolumn{4}{|l|}{ VI } & \multicolumn{4}{|l|}{ All } \\
\hline & & \multicolumn{2}{|l|}{ SP } & \multicolumn{2}{|l|}{ SH } & \multicolumn{2}{|l|}{ SP } & \multicolumn{2}{|l|}{ SH } & \multicolumn{2}{|l|}{ SP } & \multicolumn{2}{|l|}{ SH } \\
\hline $\mathrm{A}$ & $\mathrm{S}$ & $\mathrm{A}$ & $\mathrm{S}$ & $\mathrm{A}$ & $\mathbf{S}$ & $\mathrm{A}$ & $\mathrm{S}$ & $\mathrm{A}$ & $\mathrm{S}$ & $\mathrm{A}$ & $S$ & $\mathrm{~A}$ & $S$ \\
\hline 0 & 0 & 0 & 0 & 0 & 0 & 0 & 0 & 0 & 0 & 100 & 0 & 43 & 39 \\
\hline 13 & 6 & 40 & 0 & 0 & 16 & 50 & 13 & 53 & 7 & 47 & 13 & 36 & 24 \\
\hline 25 & 39 & 17 & 27 & 25 & 67 & 40 & 15 & 37 & 29 & 52 & 17 & 29 & 39 \\
\hline 20 & 43 & 55 & 9 & 25 & 22 & 63 & 6 & 31 & 19 & 53 & 7 & 23 & 35 \\
\hline 61 & 8 & 98 & 1 & 70 & 17 & 91 & 1 & 50 & 47 & 76 & 4 & 59 & 24 \\
\hline 6 & 5 & 67 & 18 & 41 & 42 & 74 & 11 & 35 & 37 & 57 & 8 & 37 & 24 \\
\hline 38 & 46 & 73 & 7 & 25 & 46 & 83 & 4 & 28 & 61 & 67 & 8 & 32 & 46 \\
\hline 30 & 47 & 63 & 17 & 38 & 50 & 65 & 13 & 22 & 54 & 58 & 15 & 28 & 47 \\
\hline 45 & 27 & 78 & 5 & 43 & 36 & 75 & 5 & 47 & 20 & 80 & 6 & 47 & 30 \\
\hline 28 & 51 & 58 & 9 & 19 & 69 & 58 & 21 & 30 & 55 & 57 & 17 & 33 & 51 \\
\hline 28 & 35 & 64 & 6 & 36 & 38 & 73 & 3 & 33 & 33 & 74 & 3 & 36 & 35 \\
\hline 29 & 44 & 59 & 12 & 50 & 45 & 64 & 11 & 31 & 62 & 65 & 12 & 36 & 48 \\
\hline 30 & 56 & 72 & 19 & 39 & 56 & 78 & 10 & 14 & 73 & 65 & 20 & 22 & 67 \\
\hline 31 & 43 & 53 & 15 & 41 & 45 & 67 & 11 & 25 & 53 & 55 & 12 & 29 & 47 \\
\hline 40 & 26 & 70 & 11 & 45 & 36 & 75 & 6 & 41 & 34 & 75 & 8 & 44 & 29 \\
\hline 55 & 26 & 65 & 7 & 48 & 20 & 68 & 15 & 34 & 47 & 67 & 14 & 41 & 41 \\
\hline 27 & 39 & 66 & 21 & 44 & 33 & 79 & 4 & 28 & 42 & 71 & 11 & 37 & 37 \\
\hline 19 & 49 & 63 & 15 & 16 & 55 & 66 & 17 & 39 & 30 & 78 & 12 & 24 & 45 \\
\hline 68 & 23 & 89 & 6 & 48 & 36 & 94 & 3 & 47 & 44 & 86 & 6 & 50 & 38 \\
\hline 66 & 22 & 59 & 24 & 46 & 30 & 77 & 14 & 40 & 25 & 72 & 13 & 49 & 37 \\
\hline 47 & 32 & 53 & 26 & 12 & 50 & 56 & 32 & 40 & 60 & 55 & 21 & 37 & 39 \\
\hline 50 & 42 & 60 & 26 & 20 & 70 & 59 & 26 & 21 & 66 & 64 & 20 & 38 & 50 \\
\hline 40 & 49 & 43 & 43 & 32 & 54 & 66 & 22 & 32 & 46 & 56 & 27 & 35 & 50 \\
\hline 30 & 49 & 47 & 32 & 35 & 52 & 62 & 15 & 13 & 78 & 59 & 22 & 28 & 54 \\
\hline 46 & 27 & 74 & 10 & 64 & 20 & 86 & 7 & 54 & 34 & 77 & 9 & 49 & 28 \\
\hline 48 & 32 & 44 & 23 & 25 & 53 & 59 & 18 & 21 & 57 & 74 & 12 & 39 & 42 \\
\hline 38 & 44 & 74 & 15 & 46 & 38 & 69 & 18 & 64 & 29 & 66 & 18 & 41 & 42 \\
\hline 59 & 34 & 62 & 17 & 54 & 41 & 68 & 12 & 37 & 53 & 69 & 17 & 48 & 42 \\
\hline 61 & 10 & 56 & 6 & 63 & 25 & 63 & 21 & 67 & 22 & 74 & 10 & 6 & 15 \\
\hline 50 & 32 & 45 & 27 & 43 & 34 & 56 & 18 & 31 & 48 & 58 & 19 & 43 & 38 \\
\hline 39 & 33 & 58 & 15 & 38 & 41 & 68 & 24 & 33 & 27 & 68 & 15 & 46 & 31 \\
\hline 21 & 47 & 28 & 36 & 15 & 52 & 31 & 28 & 8 & 52 & 36 & 29 & 21 & 47 \\
\hline 20 & 43 & 31 & 43 & 9 & 66 & 50 & 27 & 34 & 52 & 41 & 26 & 23 & 47 \\
\hline 51 & 11 & 57 & 19 & 40 & 20 & 65 & 0 & 41 & 16 & 60 & 9 & 41 & 24 \\
\hline 72 & 8 & 69 & 8 & 63 & 32 & 80 & 6 & 65 & 18 & 76 & 9 & 64 & 20 \\
\hline 49 & 40 & 69 & 10 & 61 & 18 & 62 & 9 & 53 & 33 & 63 & 9 & 53 & 28 \\
\hline 53 & 17 & 59 & 9 & 45 & 20 & 60 & 4 & 35 & 27 & 60 & 6 & 45 & 24 \\
\hline 58 & 17 & 61 & 16 & 50 & 20 & 56 & 10 & 42 & 38 & 52 & 14 & 50 & 25 \\
\hline
\end{tabular}

flanking domains. Our study clearly shows that segregation of ocular dominance columns coincides with the time of increase rather than decrease in the number of synapses situated on dendritic spines. In fact, the onset of the rapid phase of synaptogenesis begins about 1 month earlier (E112) than the onset of visible segregation of the ocular dominance domains (E144 according to Rakic, 1976, 1977b). Similar timing has been observed in Golgi preparations (Boothe et al., 1979; Lund and Holbach, 1991). Thus, only a small fraction of synaptic contacts may undergo attrition as compared to the large population that accumulates inside each ocular dominance column during the same period. However, it should be emphasized that geniculocortical terminals represent only a small fraction of the synapses situated in layer IV (LeVay and Gilbert, 1976; Fitzpatrick et al., 1985). The period of rapid synaptogenesis after birth coincides with the so-called "sensitive period" in monocularly deprived monkeys and the age when the anatomical and functional recovery is still possible if the initially deprived eye is reopened and the normal eye occluded (Hubel et al., 1977; Blakemore et al., 1978, 1981; Lund et al., 1991). Our data are consistent with the working hypothesis that the magnitude and timing of the phase of rapid production of synapses in the visual cortex before birth are determined intrinsically, while the selective stabilization of only some of these synapses may be achieved through epigenetic mechanisms (Bourgeois et al., 1986, 1989).

\section{High synaptic density during adolescence}

The high synaptic density in area 17 of the rhesus monkey, which is reached between the second and third postnatal month, 
is maintained for the next 2 years. We, however, found a slow decrease in the density during this period, which is in agreement with Zeilinski and Hendrickson (1992). This "high plateau" ends around puberty, which in this species occurs predominantly during the third year (Napier and Napier, 1967; Plant, 1988). Our results are also consistent with those from Lund and collaborators (Boothe et al., 1979; Lund and Holbach, 1991), who observed the existence of a "high plateau" or a second peak in the frequency of dendritic spines in layer IVC during the first postnatal year.

The phase of high synaplic density might be related to a continuous process of reorganization of the intracortical axonal arborizations (Callaway and Katz, 1990; Lowel and Singer, 1992) that includes a balanced production and elimination of dendritic spines (Boothe et al., 1979). This change occurs while several important visual functions continue to mature. For example, Vernier hyperacuity, which depends critically on cortical circuitry, takes more than 2 years to develop fully (Harwerth et al., 1986). Likewise, the development of spatial resolution and contrast scnsitivity in the foveal representation requires at least 1 year to reach adult levels (Vital-Durand and Blakemore, 1983).

\section{Decrease of the density of synapses during puberty}

There is general agreement among researchers in the field that synapses in the mammalian visual cortex initially have high density before they become stabilized at lower, adult levels (see introductory remarks). The conclusion that synapses between these two periods are mainly deleted rather than diluted has been discussed in previous publications on cortical synaptogenesis, which employed a similar method (Rakic et al., 1986; Zecevic et al., 1989; Zecevic and Rakic, 1991). Since we expressed our data as density of synapses per unit volume of neuropil, growth of nonsynaptic elements such as neuronal and glial cell bodies or formation of myelin sheets and enlargement of capillaries could not affect the results. Furthermore, neither the overall percentage of neuropil in the cortex nor the volume of the cortex itself changes significantly during puberty (present data; R. Williams, K. Ryder, and P. Rakic, unpublished observations). Loss of synapses is also supported by several additional considerations. For example, layers II and III display the highest decrease in synaptic density although these layers have the most steady percentage of neuropil during the life span. In contrast, layer VI, in which we have observed the largest decrease in percentage of neuropil, displays the smallest change in density of synapses. The observation that various classes of synaptic contacts have different time courses of elimination and maturation inside each layer also supports the hypothesis of synaptic elimination. For example, in layers II and III, the change in density of axodendrospine contacts stands in contrast to the relatively steady levels of axodendroshaft contacts. Likewise, the observation of a second reversal of proportions and densities of these same classes of synapses within the IVC layer cannot be explained by simple dilution of synapses in expanding cortical tissue. Finally, predominant loss of synapses situated on dendritic spines cannot be explained by the effect of uniform dilution due to growth of extrasynaptic tissue.

Although until now an absolute number of synaptic loss has not been assessed in any species, the amplitude of this transient high density appears to be larger in the cortex of human (Huttenlocher, 1979; Huttenlocher et al., 1982; Huttenlocher and De Courten, 1987) and nonhuman primates (O'Kusky and Colonnier, 1982; Rakic et al., 1986; Zielinski and Hendrickson, 1992) than in any nonprimate species examined so far (Agha- janian and Bloom, 1967; Cragg, 1975; Blue and Parnavelas, 1983). Surprisingly, such a transient high density of synapses ( $N_{a}$ only was provided here) has not been observed in the visual cortex of a prosimian primate, the tree shrew (Ungersböck et al., 1991). Our data suggest that the loss of synapses in the macaque monkey becomes more pronounced during the period of sexual maturation, between 2.7 and 5 years. This decline is more explicit when plotted against the real time (Fig. $7 C$ ) than when displayed on the logarithmic scale (Fig. $7 A, B$ ).

The loss of synapses becomes even more convincing when one estimates the total number of synapses present in the primary visual cortex at different age groups. For example, during infancy and adolescence a mean of 818 million synapses is contained in each $1 \mathrm{~mm}^{3}$ of neuropil. Since an average of $70 \%$ of the cortical volume during this period is occupied by neuropil, about 585 million synapses are contained in $1 \mathrm{~mm}^{3}$ of cortical tissue. After puberty this number is reduced to 296 million per $\mathrm{mm}^{3}$. These values expressed per $\mathrm{mm}^{3}$ of cortical tissue eliminate the issue of a possible differential growth of neuropil. According to quantitative estimations from Williams, Ryder, and Rakic (unpublished observations), the volume of area 17 decreases by only $3 \%$ : in a single hemisphere it is estimated to be $666 \pm 97 \mathrm{~mm}^{3}(n=3)$ before puberty, and $645 \pm 90 \mathrm{~mm}^{3}$ $(n=5)$ after puberty. The estimate of the total number of synapses present in the entire volume of area 17 in a single hemisphere is about $3.8 \times 10^{11}$ and $1.9 \times 10^{11}$ before and after puberty, respectively. Therefore, as many as $1.9 \times 10^{11}$ synapses may be lost between adolescence and adulthood in area 17 of each hemisphere. This $50 \%$ loss occurs predominantly between 2.7 and 5 years, which lasts $884 \mathrm{~d}$ or $76 \times 10^{6} \mathrm{sec}$. Therefore, an average of 2450 synapses may be lost per second in the striate cortex in a single cerebral hemisphere, provided that they are being eliminated equally over a $24 \mathrm{hr}$ cycle.

The loss of about 5000 synapses per second in the striate cortex of both hemispheres is by any standard an astonishing number. Quantitative results from Williams, Ryder, and Rakic (unpublished observations), using a nonbiased sampling procedure (Williams and Rakic, 1988), indicate that the total number of neurons per area 17 decreases by only $5 \%$ from infancyadolescence to adulthood. These authors came to the conclusion that $280 \pm 25(n=4)$ and $226 \pm 12(n=4)$ million neurons are present in area 17 before and after puberty, respectively. Using the mean total numbers of synapses in area 17 one can roughly estimate the numbers of synapses per neuron. This number before and after puberty is about 1391 and 717 , respectively, using the stereological correction of Anker and Cragg (1974), or 1698 and 923 using the stereological correction of Colonnier and Beaulieu (1985). Our estimates are of the same order of magnitude as those reported by O'Kusky and Colonnier (1982; see also review in Peters, 1987). Although these data represent only mean values from a highly heterogeneous population of neurons, they reveal a $45-48 \%$ loss of synapses per neuron during puberty, close to the $46 \%$ loss observed by O'Kusky and Colonnier (1982).

Changes in the density of synapses affect very little either the volume or the surface of the cortex because the total volume of synaptic boutons (the synaptopil illustrated in Fig. 2) is only a very small fraction of the cortical volume. For example, the highest density of synapses is found in one of the samples from the supragranular layers II and III, where we found 192/100 $\mu \mathrm{m}^{3}$ or 1.92 billion per $\mathrm{mm}^{3}$ of neuropil at P147. The mean length of the profiles of these synaptic contacts is $0.26 \mu \mathrm{m}$. If we assume that the synaptic contacts are basically spheres (Fig. 
2) with this mean diameter, then they would represent only $2 \%$ of $1 \mathrm{~mm}^{3}$ of the neuropil or less than $1.5 \%$ of the cortical volume, even at this exceptionally high density of synapses. Thus, a decline of synaptic number during puberty should have a rather small effect on the overall volume of the cortex.

What is the control mechanism of this synaptic loss? In recent years, studies in a variety of neural structures in diverse species revealed significant interplay between a number of diffuse substances and their specific receptors on the target cells (e.g., Purves, 1988). Temporal register of the period of synaptic loss with the period of sexual maturation points logically toward steroid hormones that have been reported to influence synaptogenesis in vivo and in vitro (e.g., Toran-Allerand, 1984; Arai and Matsumoto, 1987). A recent longitudinal study carried out in cat suggests that the period of plasticity in response to monocular deprivation lasts longer than previously thought, and actually ends only during puberty, which occurs around 1 year of age in this species (Daw et al., 1992).

\section{Comparison with maturation of subcortical visual centers}

${ }^{3} \mathrm{H}$-thymidine analysis indicates that neurogenesis in the visual system of macaque monkey begins in the retina (LaVail et al., 1991), and is followed by the onset of genesis of neurons destined for superior colliculus (Cooper and Rakic, 1981), the lateral geniculate nucleus (Rakic, 1977a), and finally the primary visual cortex (Rakic, 1974). In contrast, the same series of studies shows that the completion of neurogenesis in these same visual structures occurs in a different order: cell production stops first in the lateral geniculate nucleus, then in the superior colliculus, followed by the visual cortex, while it continues in the retina where the rod photoreceptors are being generated up to the term. Neither the sequence of onset nor the sequence of completion of neurogenesis correlates well with the onset and course of synaptogenesis in structures of primary visual pathway. Thus, we have observed the first synaptic contacts in layer I of the striate cortex already at E50. Synaptic contacts appear in the lateral geniculate nucleus almost 2 weeks later, at E62 (Hendrickson and Rakic, 1977). They have been observed first between E70 and E78 in the perifoveal region of the retina (Nishimura and Rakic, 1985), but synaptogenesis in the fovea may start somewhat earlier. The first synapses in the entire visual system were recorded in the superior colliculus at E47 (Cooper and Rakic, 1983). Overall, the onset of synaptogenesis seems to be initiated earlier in the central visual structures (Nishimura and Rakic, 1987; reviewed in Williams and Rakic, 1988). However, a subsequent course of synaptic production in various visual centers of the rhesus monkey occurs rather asynchronously. For example, in the perifoveal regions of the inner plexiform layer of the retina, the rapid phase of synaptogenesis takes place during the midgestational period and the maximum of density is reached 2 months before the time of birth (Nishimura and Rakic, 1985). In contrast, the rapid phase of synaptogenesis in the striate cortex takes place mostly during the neonatal period and reaches the maximum value during the third month after birth. These data are consistent with the concept that the individual visual centers mature functionally at different rates (see review in Boothe et al., 1985).

The density of synaptic contacts per unit volume of neuropil in the striate cortex of adult monkeys is comparable to that in other areas counted from the same set of animals (Rakic et al., 1986). As a comparison, data from the motor cortex (Zecevic et al., 1989), somatosensory cortex (Zecevic and Rakic, 1991), the prefrontal association cortex (J.-P. Bourgeois and P. S. Gold-
man-Rakic, unpublished observations), the anterior cingulate cortex (Granger and Bourgeois, unpublished observations), and the hippocampus (Eckenhoff and Rakic, 1991) suggest that, despite differences in the cytoarchitectonic composition, pattern of extrinsic projections, and the intracortical circuitry, the global kinetics of synaptic production seem to be under similar constraints in the entire cortical mantle (Rakic et al., 1986). Biochemical (Goldman-Rakic and Brown, 1982) and histochemical data (Foote and Morrison, 1984) suggest that concentrations of noradrenaline and 5-HT increase rapidly in the visual cortex of the macaque, over the first 2 postnatal months, and approach adult levels between 3 and 5 postnatal months. The development of neurotransmitter receptor sites in the macaque visual cortex also occurs concurrently with a maximal density being attained between 2 and 4 months after birth (Lidow et al., 1991; Lidow and Rakic, 1992). Although the present study displays evidence for the existence of differences in the tempo of maturation of distinct populations of synapses in different cortical layers, these differences remain within a general synchronous "maturational envelope," which proceeds according to the same time course in the entire cortical mantle.

\section{Changes in ratios of contacts on spines versus shafts}

Although the overall production of synapses occurs concurrently across all layers in the diverse cortical areas (Rakic et al., 1986), individual synaptic subclasses may follow a separate time course (see also Lund and Holbach, 1991). For example, during the postnatal period the density of axodendrospine synapses is higher than that of axodendroshaft contacts in all cortical layers. Furthermore, the transient high density of synapses is generally more accentuated in the supragranular layers. The relative proportion of synaptic contacts found on dendritic shafts versus spines is reversed about 3 weeks prior to birth when the rate of synaptogenesis on spines begins to accelerate. This reversal occurs simultaneously in other neocortical areas (Zecevic et al., 1989; Zecevic and Rakic, 1991) as well as in the hippocampal formation (Eckenhoff and Rakic, 1991) and the neostriatum (Brand and Rakic, 1984).

The accumulation of synapses situated on dendritic spines is completed within the first 2 postnatal months in all layers except IV, where the peak density is reached considerably earlier (P14$\mathrm{P} 21$ ). This accumulation occurs in parallel with the early growth of the dendritic spines in this layer (Lund and Holbach, 1991). However, proportions of synapses situated on spines and on shafts in sublayer IVC undergo a second reversal during the seventh month while the proportions of the symmetric contacts remain unchanged. This finding suggests that the majority of synapses on the dendritic shafts formed during this period are asymmetric. The transiently high density of asymmetric synaptic contacts on spines in this layer may be followed by a second, slower, but more prolonged phase of high density of contacts located on the shafts. The timing of the first reversal of the proportions and densities of synaptic contacts occurs in utero, before exposure of the animal to visual stimulation. On the other hand, the second reversal occurs several months after birth, and, therefore, may be related to the late maturation of spatial resolution, contrast sensitivity, or binocular vision (Vital-Durand and Blakemore, 1983; Harwerth et al., 1986). The ratio of synaptic contacts on spines and shafts stabilizes around puberty. It should be pointed out, however, that the second reversal in layer IV was not observed in the prefrontal (Bourgeois et al., unpublished observations) or somatosensory cortex (Zecevic and Rakic, 1991) in the same set of specimens. Our 
observations that the transient period of high density of synapses on dendritic spines lasts for a shorter time in the granular layers than in either supra- or infragranular layers, along with the results of visual deprivation experiments in macaque (LeVay et al., 1980) and cat (Daw et al., 1992), provide an explanation why neuronal plasticity lasts longer in the upper and lower cortical layers than in the granular layers.

\section{Individual variability}

Individual variability in the density of synaptic contacts during the rapid phase of production is relatively small. However, in the phase of elimination the densities of synaptic contacts begin to display considerable intra- and interindividual variability. It is possible that the rapid phase of synaptogenesis yields more homogeneous samples because it is controlled by a common intrinsic mechanism (Rakic et al., 1986). In contrast, the phases of synaptic elimination may display higher individual variability because of the diverse epigenetic events and variety of environmental factors that become more pronounced postnatally (Bourgeois et al., 1989). The same variability was also observed in the other cortical areas at the same ages (Zecevic et al., 1989; Zecevic and Rakic, 1991; Bourgeois and Goldman-Rakic, unpublished observations). It seems to be unrelated to the thickness of section's or number of probes examined, and it is amplified by the stereological corrections. Use of the vertical probes in the present study does not appear to be the source of this variability, since a comparable level of individual variability was found in the anterior cingulate cortex when horizontal probes confined to each cortical layer were made out of the blocks obtained from the very same set of animals (Granger and Bourgeois, unpublished observations; see Zecevic and Rakic, 1991). The density of the different types of synapses also varies between the neighboring sample points along the lamina IV in the primary visual cortex of the cat (Winfield, 1983), as well as the lamina II of the rat (Wolff, 1976). An amplitude of variability, similar to the one reported here, was also observed during the development of axodendritic spines (Boothe et al., 1979; Lund and Holbach, 1991) and axosomatic contacts in layer IVC in area 17 of the same species (Mates and Lund, 1983b; Lund and Harper, 1991). Finally, high variability has been found also in the number of neurons in the macaque neocortex (Vincent et al., 1989; Williams, Ryder, and Rakic, unpublished observations) and in the concentrations of several neurotransmitters (Wenk et al., 1989) and neurotransmitter receptors (Rakic et al., 1988). Thus, there is little doubt that there are considerable quantitative differences of synaptic density in macaque visual cortex, though the significance of these differences remains to be determined.

\section{References}

Aghajanian GK, Bloom FE (1967) The formation of synaptic junctions in developing rat brain: a quantitative electron microscopy study. Brain Res 6:716-727.

Anker RL, Cragg BC (1974) Estimation of the number of synapses in a volume of nervous tissue from counts in thin sections by electron microscopy. J Neurocytol 3:725-735.

Arai Y, Matsumoto A (1987) Gonadal steroid control of synaptogenesis in the neuroendocrine brain. In: Endocrinology and physiology of reproduction (Leung PCK, Armstrong DT, Ruf KB, Fresen HG, eds), pp 13-21. New York: Plenum.

Billings-Gagliardy S, Chan-Palay V, Palay SL (1974) A review of lamination in area 17 of the visual cortex of Macaca mulatta. J Neurocytol 3:619-629.

Blakemore C, Garey LJ, Vital-Durand F (1978) The physiological effects of monocular deprivation and their reversal in the monkey's visual cortex. J Physiol (Lond) 283:223-262.

Blakemore C, Garey LJ, Vital-Durand F (1981) Recovery from monocular deprivation in the monkey. I. Reversal of physiological effects in the visual cortex. Proc R Soc Lond [Biol] 213:399-423.

Blue ME, Parnavelas JG (1983) The formation and maturation of synapses in the visual cortex of the rat. II. Quantitative analysis. J Neurocytol 12:697-712.

Boothe RG, Greenough WT, Lund JS, Wrege K (1979) A quantitative investigation of spine and dendrite development of neurons in visual cortex (area 17) of Macaca nemestrina monkeys. J Comp Neurol 186: $473-490$.

Boothe RG, Dobson V, Teller DY (1985) Postnatal development of vision in human and nonhuman primates. Annu Rev Neurosci 8:495545.

Bourgeois J-P, Toutant M, Gouzé JL, Changeux J-P (1986) Effect of activity on the selective stabilization of the motor innervation of fast muscle posterior latissimus dorsi from chick embryo. Int J Dev Neurosci 4:415-429.

Bourgeois J-P, Jastreboff PJ, Rakic P (1989) Synaptogenesis in visual cortex of normal and preterm monkeys: evidence for intrinsic regulation of synaptic overproduction. Proc Natl Acad Sci USA 86:42974301.

Brand S, Rakic P (1984) Cytodifferentiation and synaptogenesis in the neostriatum of the fetal and neonatal monkeys. Anat Embryol (Berl) 169:21-34.

Callaway EM, Katz LC (1990) Emergence and refinement of clustered horizontal connections in cat striate cortex. J Neurosci 10:1134-1153.

Colonnier M (1968) Synaptic patterns on different cell types in the different laminae of the cat visual cortex. An electron microscopic study. Brain Res 9:268-287.

Colonnier M (1981) The electron-microscopic analysis of the neuronal organization of the cerebral cortex. In: The organization of the cerebral cortex (Schmitt FO, Worden FG, Dennis SD, eds), pp 125-152. Cambridge, MA: MIT Press.

Colonnier M, Beaulieu C (1985) An empirical assessment of stereological formulae applied to the counting of synaptic disks in the cerebral cortex. J Comp Neurol 231:175-179.

Cooper ML, Rakic P (1981) Neurogenetic gradients in the superior and inferior colliculus of the rhesus monkey. J Comp Neurol 202: 309-334.

Cooper ML, Rakic P (1983) Gradients of cellular maturation and synaptogenesis in the superior colliculus of the fetal rhesus monkey. J Comp Neurol 215:165-186.

Coupland RE (1968) Determining sizes and distribution of sizes of spherical bodies such as chromaffin granules in tissue sections. Nature 217:384-388.

Cragg BG (1975) The development of synapses in the visual system of the cat. J Comp Neurol 160:147-166.

Daw NW, Fox K, Sato H, Czepita D (1992) Critical period for monocular deprivation in the cat visual cortex. J Neurophysiol 67:197-202.

Eckenhoff MF, Rakic P (1991) Synaptogenesis in the dentate gyrus of the rhesus monkey during pre- and postnatal life. Dev Brain Res 564: 129-135.

Fitzpatrick D, Lund JS, Blasdel GG (1985) Intrinsic connections of macaque striate cortex: afferent and efferent connections of lamina 4C. J Neurosci 5:3329-3349.

Foote SL, Morrison JH (1984) Postnatal development of laminar innervation patterns by monoaminergic fibers in monkey (Macaca fascicularis) primary visual cortex. J Neurosci 4:2667-2680.

Goldman-Rakic PS, Brown RM (1982) Postnatal development of monoamine content and synthesis in the cerebral cortex of rhesus monkeys. Brain Res 4:339-349.

Harwerth RS, Smith EL III, Duncan GC, Crawford MLJ, Von Norden GK (1986) Multiple sensitive periods in the development of the primate visual system. Science 232:235-238.

Hendrickson A, Rakic P (1977) Histogenesis and synaptogenesis in the dorsal lateral geniculate nucleus (LGd) of the fetal monkey brain. Anat Rec 187:602.

Hubel DH, Wiesel TN (1977) Functional architecture of macaque monkey visual cortex. Proc R Soc Lond [Biol] 198:1-59.

Hubel DH, Wiesel TN, LeVay S (1977) Plasticity of ocular dominance 
columns in monkey striate cortex. Philos Trans R Soc Lond [Biol] 278:377-410.

Huttenlocher PR (1979) Synaptic density in human frontal cortex, developmental changes and effects of aging. Brain Res 163:195-205.

Huttenlocher PR, de Courten C (1987) The development of synapses in striate cortex of man. Hum Neurobiol 6:1-9.

Huttenlocher PR, de Courten C, Garey LJ, Van der Loos H (1982) Synaptogenesis in the human visual cortex. Evidence for synapse elimination during normal development. Neurosci Lett 33:247-252.

Jones EG (1986) Neurotransmitters in the cerebral cortex. J Neurosurg 65:135-153.

Kuljis RO, Rakic P (1989) Multiple types of neuropeptide Y-containing neurons in primate neocortex. I Comp Neurol 280:369-385

LaMantia A-S, Rakic P (1990) Axon overproduction and elimination in the corpus callosum of the developing rhesus monkey. J Neurosci 10:2156-2175.

LaVail MM, Rapaport DH, Rakic P (1991) Cytogenesis in monkey retina. J Comp Neurol 309:86-1 14.

LeVay S, Gilbert CD (1976) Laminar patterns of geniculu-cortical projection in the cat. Brain Res 113:1-19.

LeVay S, Stryker MP (1979) The development of ocular dominance columns in the cat. In: Symposium: aspects of developmental neurobiology (Fernandelli JA, ed), pp 83-98, Society for Neuroscience.

LeVay S, Wiesel TN, Hubel DH (1980) The development of ocular dominance columns in normal and visually deprived monkeys. $J$ Comp Neurol 191:1-51.

Lidow M, Goldman-Rakic PS, Rakic P (1991) Synchronized development of neurotransmitter receptors in diverse regions of the primate cerebral cortex. Proc Natl Acad Sci USA 88:10218-10221.

Lidow MS, Rakic P (1992) Postnatal development of monoaminergic neurotransmitter receptors with primate neocortex. Cereb Cortex $2: 401-415$

Lowel S, Singer W (1992) Selection of intrinsic horizontal connections in the visual cortex by correlated neuronal activity. Science 255:209212.

Lund JS (1973) Organization of neurons in the visual cortex, area 17, of the monkey (Macaca mulatta). J Comp Neurol 147:455-496.

Lund JS, Harper TR (1991) Postnatal development of thalamic recipient neurons in the monkey striate cortex: III. Somatic inhibitory synapse acquisition by spiny stellate neurons of layer $4 \mathrm{C}$. J Comp Neurol 309:144-149.

Lund JS, Holbach SM (1991) Postnatal development of thalamic recipient neurons in the monkey striate cortex: I. Comparison of spine acquisition and dendritic growth of layer $4 \mathrm{C}$ alpha and beta spiny stellate neurons. J Comp Neurol 309:115-128.

Lund JS, Holbach SM, Chung WW (1991) Postnatal development of thalamic recipient neurons in the monkey striate cortex: II. Influence of afferents driving on spine acquisition and dendritic growth of layer 4C spiny stellate neurons. J Comp Neurol 309:129-140.

Mates SL, Lund JS (1983a) Developmental changes in the relationship between type 1 synapses and spiny neurons in the monkey visual cortex. J Comp Neurol 221:91-97.

Mates SL, Lund JS (1983b) Developmental changes in the relationship between type 2 synapses and spiny neurons in the monkey visual cortex. J Comp Neurol 221:98-105.

Mayhew TM (1979) Stereological approach to the study of synapse morphometry with particular regard to estimating numbers in a volume and on a surface. $J$ Neurocytol 8:121-138.

Napier JR, Napier PH (1967) A handbook of living primates. New York: Academic.

Nishimura Y, Rakic P (1985) Development of the rhesus monkey retina. I. Emergence of the inner plexiform layer and its synapses. J Comp Neurol 241:420-434.

Nishimura Y, Rakic P (1987) Development of the rhesus monkey retina. II. A three-dimensional analysis of the sequences of synaptic combinations in the inner plexiform layer. J Comp Neurol 262:290313.

O'Kusky J, Colonnier M (1982) Postnatal changes in the number of neurons and synapses in the visual cortex (area 17) of the macaque monkey: a stereological analysis in normal and monocularly deprived animals. J Comp Neurol 210:291-306

Peters A (1987) Number of neurons and synapses in primary visual cortex. In: Cerebral cortex, Vol 6, Chap 7 (Peters A, Jones EG, eds), pp 267-294. New York: Plenum.
Peters A, Palay SL, Webster Hide F (1976) The fine structure of the nervous system. Philadelphia: Saunders.

Plant TM (1988) Neuroendocrine basis of puberty in the monkey (Macaca mulatta). In: Frontiers of neuroendocrinology, Vol 10 (Martin L, Ganong WF, eds), pp 215-238. New York: Raven.

Purves D (1988) Body and brain: a trophic theory of neuronal connections. Cambridge, MA: Harvard UP.

Rakic $P$ (1972) Mode of cell migration to the superficial layers of fetal monkey neocortex. J Comp Neurol 145:61-84.

Rakic P (1973) Kinetics of proliferation and latency between final division and onset of differentiation of the cerebellar stellate and basket neurons. J Comp Neurol 147:523-546.

Rakic P (1974) Neurons in rhesus monkey visual cortex: systematic relation between time of origin and eventual disposition. Science 183: 425-427.

Rakic P (1975) Timing of major ontogenetic events in the visual cortex of the rhesus monkey. In: Brain mechanisms in mental retardation (Buchwald NA, Brazier M, eds), pp 3-40. New York: Academic.

Rakic $P$ (1976) Prenatal genesis of connections subserving ocular dominance in the rhesus monkey. Nature 261:467-471.

Rakic P (1977a) Genesis of dorsal lateral geniculate nucleus in the rhesus monkey: site and time of origin, kinetics of proliferation, routes of migration and pattern of distribution of neurons. J Comp Neurol $176: 23-52$.

Rakic P (1977b) Prenatal development of the visual system in rhesus monkey. Philos Trans R Soc Lond [Biol] 278:245-260.

Rakic $P$ (1978) Neuronal migration and contact guidance in primate telencephalon. Postgrad Med J 54:25-40.

Rakic P (1988) Specification of cerebral cortical areas. Science 241: 170-176.

Rakic P, Yakovlev PI (1968) Development of the corpus callosum and cavum septi in man. J Comp Neurol 132:45-72.

Rakic P, Bourgeois JP, Eckenhoff MF, Zecevic N, Goldman-Rakic PS (1986) Concurrent overproduction of synapses in diverse regions of the primate cerebral cortex. Science 232:232-235.

Rakic P, Gallager D, Goldman-Rakic PS (1988) Areal and laminar distribution of major neurotransmitter receptors in the monkey visual cortex. J Neurosci 8:3670-3690.

Small JV (1968) Measurements of section thickness. In: Proceedings of the 4th European Congress on Electron Microscopy, Vol 1 (Bocciarelli DS, ed), p 609. Rome: Tipografia Poliglotta Vaticana.

Somogyi P (1989) Synaptic organization of GABAergic neurons and $\mathrm{GABA}_{\mathrm{A}}$ receptors in the lateral geniculate nucleus and visual cortex. In: Neuronal mechanisms of visual perception (Lam DK, Gilbert CD, eds), pp 35-65. Houston, TX: Portfolio.

Toran-Allerand D (1984) On the genesis of sexual differentiation of the central nervous system: morphogenetic consequences of steroidal exposure and possible role of $\alpha$-Feto protein. Prog Brain Res 61:6378

Ungersböck A, Kretz R, Rager G (1991) Synaptogenesis in the primary visual cortex of the tree shrew (Tupaia belengeri). J Comp Neurol 308:491-504.

Van Essen DC, Newsome WT, Maunsell JH (1984) The visual field representation in striate cortex of the macaque monkey: asymmetries, anisotropies, and individual variability. Vision Res 24:429-448.

Vincent SL, Peters A, Tigges J (1989) Effects of aging on the neurons within area 17 of rhesus monkey cerebral cortex. Anat Rec 223:329341.

Vital-Durand F, Blakemore C (1983) The first few weeks in monkey's visual cortex. Behav Brain Res 8:283.

Wenk GL, Pierce DJ, Struble RG, Price DL, Cork LC (1989) Agerelated changes in multiple neurotransmitter systems in the monkey brain. Neurobiol Aging 10:11-19.

Williams RW, Rakic P (1988) Elimination of neurons from the rhesus monkey's lateral geniculate nucleus during development. J Comp Neurol 272:424-436.

Winfield DA (1983) The postnatal development of synapses in the different laminae of the visual cortex in the normal kitten and in kittens with eyelid suture. Dev Brain Res 9:155-169.

Wolff JR (1976) Stereological analysis of the heterogeneous composition of the central nervous tissue: synapses of the cerebral cortex In: Proc 4th Int Congr for Stereology. National Bureau of Standards, special publication 431:331-334.

Yakovlev PI, Lecours AR (1967) The myelogenetic cycles of regional 
maturation of the brain. In: Regional development of the brain in early life (Minkowski A, ed), pp 3-70. Oxford: Blackwell.

Zecevic N, Rakic P (1991) Synaptogenesis in the primary somatosensory cortex of the rhesus monkey during fetal and postnatal life. Cereb Cortex 1:510-523.
Zecevic N, Bourgeois J-P, Rakic P (1989) Changes in synaptic density in motor cortex of rhesus monkey during fetal and postnatal life. Dev Brain Res 50:11-32.

Zielinski BS, Hendrickson AE (1992) Development of synapses in macaque monkey striate cortex. J Vis Neurosci 8:491-504. 